\title{
Cardiotoxicity of Novel Targeted Hematological Therapies
}

\author{
Valentina Giudice ${ }^{1,2, *(0)}$, Carmine Vecchione ${ }^{1,3}$ and Carmine Selleri ${ }^{1,4}$ \\ 1 Department of Medicine, Surgery and Dentistry "Scuola Medica Salernitana”, University of Salerno, \\ Baronissi, 84081 Salerno, Italy; cvecchione@unisa.it (C.V.); cselleri@unisa.it (C.S.) \\ 2 Clinical Pharmacology, University Hospital "San Giovanni di Dio e Ruggi D’Aragona”, 84131 Salerno, Italy \\ 3 IRCCS Neuromed (Mediterranean Neurological Institute), 86077 Pozzilli, Italy \\ 4 Hematology and Transplant Center, University Hospital "San Giovanni di Dio e Ruggi D'Aragona”, \\ 84131 Salerno, Italy \\ * Correspondence: vgiudice@unisa.it; Tel.: +39-089-672-493
}

Received: 9 November 2020; Accepted: 10 December 2020; Published: 11 December 2020

\begin{abstract}
Chemotherapy-related cardiac dysfunction, also known as cardiotoxicity, is a group of drug-related adverse events negatively affecting myocardial structure and functions in patients who received chemotherapy for cancer treatment. Clinical manifestations can vary from life-threatening arrythmias to chronic conditions, such as heart failure or hypertension, which dramatically reduce quality of life of cancer survivors. Standard chemotherapy exerts its toxic effect mainly by inducing oxidative stress and genomic instability, while new targeted therapies work by interfering with signaling pathways important not only in cancer cells but also in myocytes. For example, Bruton's tyrosine kinase (BTK) inhibitors interfere with class I phosphoinositide 3-kinase isoforms involved in cardiac hypertrophy, contractility, and regulation of various channel forming proteins; thus, off-target effects of BTK inhibitors are associated with increased frequency of arrhythmias, such as atrial fibrillation, compared to standard chemotherapy. In this review, we summarize current knowledge of cardiotoxic effects of targeted therapies used in hematology.
\end{abstract}

Keywords: cardiotoxicity; targeted therapy; adverse reactions; hematology

\section{Introduction}

In last decades, scientific advances in onco-hematology have significantly improved outcomes of cancer patients who have become long-term survivors; however, they must face late and long-term treatment-related effects that worsen their quality of life [1]. In particular, chemotherapy-related cardiac adverse events, also known as cardiotoxicity, represent the most common cause of death in long-term survivors-children after 15-25 years of cancer diagnosis have a cumulative incidence of heart failure (HF) of $4.4 \%$ and a rate of cardiac death 8.2-fold higher than the age- and sex-matched general population [2,3]. Myocardial disfunction and HF are the most common and life-threatening manifestations. Cardiotoxicity can also display as coronary artery disease (CAD), valvular diseases, arrhythmias, peripheral vascular disease (PAD) or stroke, arterial hypertension, and any other cardiovascular manifestations, such as pulmonary hypertension [1,4-6]. Cardiotoxicity can be evident right after the first dose exposure to several years after the end of treatment depending on patient's characteristics, disease biology, type of chemotherapy administered, and cumulative dose [1]. Therefore, patients should be regularly monitored to early identify and treat cardiotoxicity, and echocardiography is the most used, simple, and widely accessible method for monitoring cardiac function and vascular system [1,7]. For example, echocardiography can be used for early detection of chemotherapy-related cardiac dysfunction (CTRCD), defined as a persistent reduction of the left 
ventricular ejection fraction (LVEF) $>10 \%$ compared to baseline levels and confirmed 2 to 3 weeks after the first measurement $[1,8]$. Prolonged augmented circulating troponin levels might also help in early detection of left ventricular (LV) dysfunction during chemotherapy treatment, while (N-terminal pro) brain natriuretic peptide (BNP/NT-proBNP) levels can increase after therapy [9].

Cardiotoxicity caused by "old" standard chemotherapeutic drugs, such as alkylating agents and anthracyclines, or first-generation targeted therapies, such as tyrosine kinase inhibitors (TKIs), is well-known and characterized. Chemotherapy is employed for treatment of Hodgkin and non-Hodgkin lymphomas, myeloid and lymphoid leukemias, and before hematopoietic stem cell transplantation as conditioning regimens. Chemotherapy-related cardiac complications and mortality have been historically reported at high incidence rates in earlier studies; however, optimization of cumulative dosage, such as introduction of reduced-intensity conditioning regimens, or different chemotherapeutic scheme, such as from combination of vincristine, methotrexate, cyclophosphamide, and prednisone (MOMP) to adriamycin, bleomycin, vinblastine, and dacarbazine (ABVD) for treatment of Hodgkin lymphoma, has significantly reduced the impact of cardiotoxicity in hematological patients $[10,11]$. In the last decades, standard chemotherapy has also been associated or replaced with novel targeted therapies that are used for rescue refractory/relapsed patients. Cardiac adverse events of novel targeted therapies are still under investigation because of the short available follow-up, especially for recently approved drugs [1]. In this review, we provide an update of cardiotoxic effects of novel targeted therapies used in malignant hematological disorders with a particular focus on TKIs, proteasome inhibitors, immunomodulatory drugs (IMiDs), and demethylating agents.

\section{TKIs}

TKIs are a group of drugs that selectively inhibit tyrosine kinases, enzymes responsible of signal transduction after receptor stimulation by adding a phosphate group from ATP to a tyrosine residue on proteins [12]. In several hematological disorders, tyrosine kinases are constitutionally activated, leading to a deregulation of signaling pathways involved in cell survival and proliferation [13]. For example, in chronic myeloid leukemia (CML), a reciprocal translocation (9;22)(q34;q11), known as "Philadelphia chromosome" $(\mathrm{Ph})$, determines the formation of a fusion protein, B cell receptor $(\mathrm{BCR}) / \mathrm{ABL}$, that activates various intracellular pathways, such as signal transducer and activator of transcription 5 (STAT5) and phosphoinositide 3-kinase (PI3K) signaling pathways, leading to increased cell survival and proliferation. Therefore, by blocking this kinase with specific inhibitors, neoplastic clone growth and survival is halted, favoring apoptosis and cell death and thus reducing tumor burden [12].

\subsection{Bruton's Tyrosine Kinase Inhibitors}

Bruton's tyrosine kinase (BTK), a non-receptor member of TEC kinase family, is essential for B cell development as mutations in BTK cause a primary immunodeficiency $X$-linked agammaglobulinemia [14]. BTK is important in downstream of $B$ cell receptor (BCR) and chemokine signaling cascades, and in cell survival because BCR engagement increases anti-apoptotic protein expression and S-phase cyclins [15-17]. In addition, BTK plays a crucial role in cell adhesion signaling pathways, including integrin $\alpha 4 \beta 1$ (VLA-4) and vascular cell adhesion molecule-1 (VCAM-1)/fibronectin pathways [18]. In particular, VLA-4 is involved in bone marrow (BM) homing and retention of hematopoietic cells because of its ability to interact with VCAM-1 on BM stromal cells [18-20]. Moreover, VLA-4 can interact with CD38 and form the macromolecular complex involved in trans endothelial rolling, invasion, arrest, and survival of the neoplastic clone in BM and lymphoid tissues [18,21]. These BTK functions are essential in survival and proliferation of malignant cells in various non-Hodgkin lymphomas (NHL), such as chronic lymphocytic leukemia (CLL) and mantle cell lymphoma (MCL) [14]. Therefore, BTK inhibitors can block tumor growth and induce apoptosis in neoplastic cells.

Ibrutinib, an oral irreversible BTK inhibitor, covalently binds the 481 cysteine of the kinase domain, blocking BTK activity but not interactions with Syk, and has been approved in 2016 for 
treatment of CLL, MCL, and Waldenström's macroglobulinemia [14]. Despite its short life in clinical practice, ibrutinib is already known to cause cardiotoxicity, especially arrhythmias and hypertension, probably because of interactions with PI3K and other TEC pathways involved in cardiac protection under stress conditions (Figure 1) [22-26]. BTK inhibitors can interfere with all class I PI3K isoforms (PI3K $\alpha$, $\mathrm{PI} 3 \mathrm{~K} \alpha, \mathrm{PI} 3 \mathrm{~K} \gamma$, and PI3K $\delta$ ), differently expressed in various tissues and involved in cardiac functions. Class I PI3K $\alpha$ has an essential role in physiological cardiac hypertrophy and contractility, and is activated in cardiomyocytes by insulin or insulin-like growth factor-1 (IGF-1), while in endothelial cells, fibroblasts and vascular smooth muscle cells by fibroblast growth factor (FGF), platelet-derived growth factor (PDGF), and vascular endothelial growth factor (VEGF). In mouse models, PI3K $\alpha$ suppression worsens hypertrophic cardiomyopathy caused by pressure overload or myocardial infarction (MI), while PI3K $\alpha$ activation ameliorates hypertrophic and dilated cardiomyopathy $[27,28]$. PI3K $\alpha$ is also involved in regulation of various channel-forming proteins, such as $\mathrm{K}^{+}$: $\mathrm{Kir}, \mathrm{Ca}^{2+}$ : Cav1, or $\mathrm{Na}^{+}$: SCN5A; direct inhibition of PI3K $\alpha$ or at the receptor level (e.g., by ibrutinib) causes activation of late Na current (INa-L) through PIP3 reduction, resulting in enhanced action potential and QT prolongation. In addition, PI3K $\alpha$ inhibition affects L-type $\mathrm{Ca}^{2+}$ current $(\mathrm{ICa}, \mathrm{L})$, and modulates $\mathrm{Ca}^{2+}$ cycling and $\alpha$-adrenergic stimulation favoring action potential prolongation, abnormal automaticity, and early and delayed afterdepolarization [27]. While PI $3 \mathrm{~K} \gamma$, mainly expressed in leukocytes and cardiac cells, is upregulated during atherosclerosis, it has opposite inotropic functions compared to $\mathrm{PI} 3 \mathrm{~K} \alpha$, and decreases myocardial $\beta$-adrenergic receptor $(\beta-A R)$ under stress conditions, such as during congestive heart failure (CHF) $[27,29]$. Therefore, the use of agents that block the activation of INa-L (e.g., ranolazine) or upregulate ion channel expression might reduce the impact of PI3K inhibition-related cardiotoxicity [27,30].

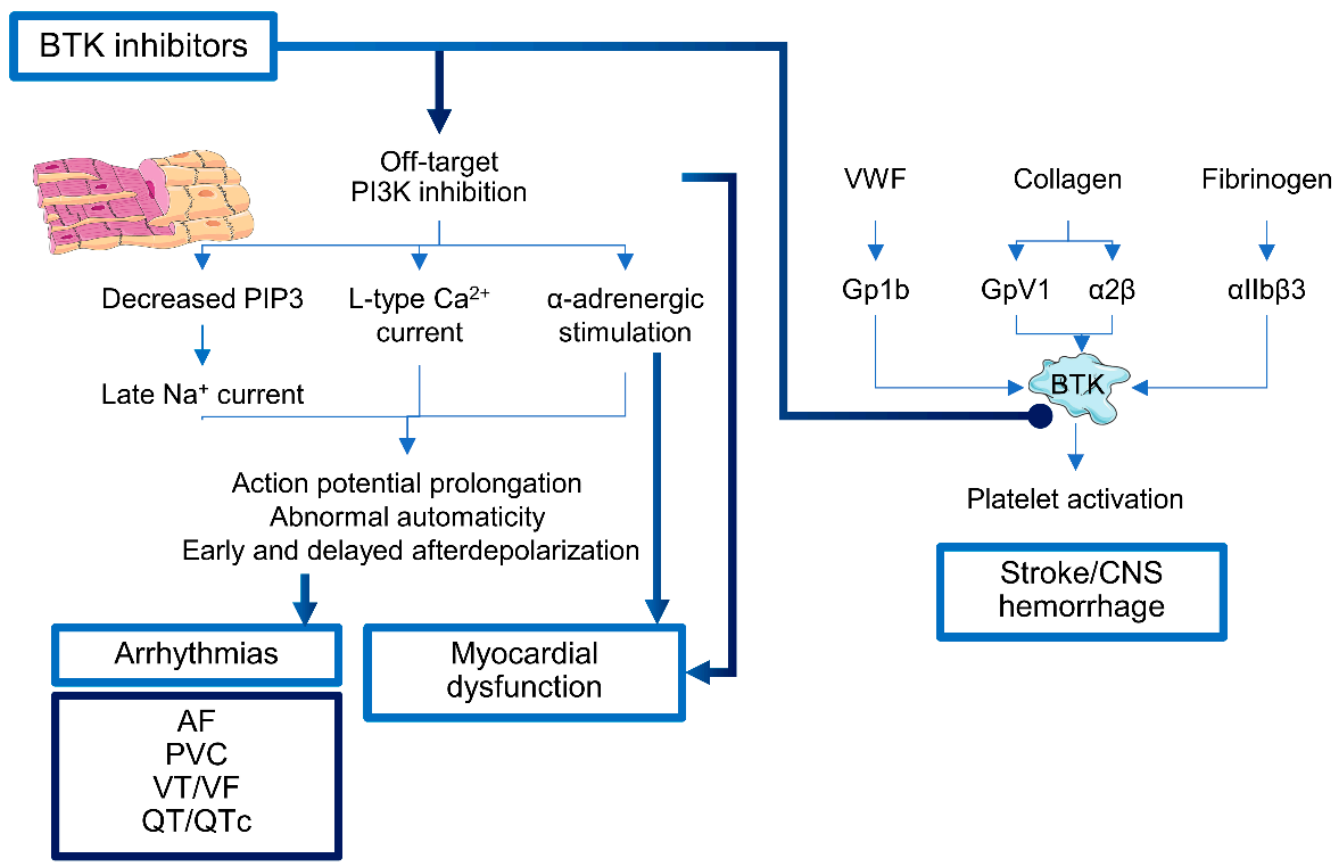

Figure 1. Cardiotoxicity of Bruton's tyrosine kinase (BTK) inhibitors. BTK inhibitors can interfere with phosphoinositide 3-kinase (PI3K) pathways in cardiomyocytes, influence normal ion current, and cause action potential prolongation and abnormal automaticity leading to arrhythmias, such as atrial fibrillation (AF), premature ventricular contractions (PVC), ventricular tachycardia or fibrillation (VT/VF), and QT interval prolongation (QT/QTc). In platelets, BTK is activated by Von-Willebrand factor (VWF), collagen, and fibrinogen binding to cognate glycoproteins (e.g., Gp1b), leading to platelet activation. BTK inhibition in platelets is associated to central nervous system (CNS) bleeding or ischemia. 
The most common ibrutinib-associated arrhythmia is atrial fibrillation (AF), with an incidence of 5.77 per 100 person-years (PY) over a median follow-up of 18.3 months, significantly higher than that of general population [31,32]. Incidence of AF is increased in patients receiving ibrutinib compared to standard chemotherapy (6.5\% vs. $1.6 \%$ over a 16.6 month follow-up), higher in combination with other drugs $(7.7 \%$ vs. $5.8 \%$ of ibrutinib alone; HELIOS study) or longer follow-up (10.4\% over a 78 month period). Median time to AF onset is 2.8 months, and incidence at 6 months is $5.3 \%$ [33]. Most patients develop de novo AF, and CLL subjects are more susceptible to this adverse event compared to MCL (7.0\% vs. $4.3 \%)$. Other risk factors for ibrutinib-associated AF are prior history of AF, age $>65$ years, pre-existing hypertension and hyperlipidemia, and high Shanafelt risk score category in CLL. Prior CAD, valvular disease, and diabetes are not associated with increased risk of $\mathrm{AF}$ [33], while previous use of angiotensin-converting enzyme inhibitors (ACE-Is), angiotensin receptor blockers (ARBs), beta-blockers, and aspirin are associated with increased risk of AF in patients treated with ibrutinib [34]. Ventricular arrhythmias, such as QT/QTc prolongation, premature ventricular contractions (PVCs), non-sustained ventricular tachycardia (VT), ventricular fibrillation, and sudden cardiac death are also reported with a cumulative incidence of 1991 events per 100,000 PY [35-37].

Other forms of ibrutinib-associated cardiotoxicity are arterial hypertension, central nervous system (CNS) hemorrhagic or ischemic events, cardiomyopathy, and HF [38]. Arterial hypertension is a common cardiac adverse event during ibrutinib treatment, with a cumulative incidence of $78 \%$ and a variable median time to peak of blood pressure (BP) from 1.8 to 6 months; however, hypertension can develop after a very short time from initiation, and thus a close monitoring of patients in early months of ibrutinib treatment is required [39-42]. Newly diagnosed or worsening of a pre-existing hypertension during ibrutinib treatment is associated with a higher incidence of major adverse cardiovascular events, especially AF $[39,40]$. CNS hemorrhages or ischemia can frequently occur [38]. These contrasting events might be related to the ability of BTK inhibitors to variously interfere with platelet glycoprotein $\mathrm{Ib}(\mathrm{GPIb})$ and GPVI signaling pathways and to alter interactions with von Willebrand factor (VWF) [43]. Indeed, ibrutinib and second generation BTK inhibitor acalabrutinib might impair thrombus formation on atherosclerotic plaques and interfere with platelet functions and aggregation [34,43]. An increased bleeding risk is also related to pharmacologic interactions between ibrutinib and anticoagulants, such as apixaban, rivaroxaban, and dabigatran, metabolized by cytochrome CYP3A4 leading to augmented plasma concentrations [34].

\subsection{PI3K Inhibitors}

PI3K pathway plays an important role in B cell development, adhesion and migration, proliferation and survival, and immune functions [44]. Three PI3K inhibitors have been approved by the U.S. Food and Drug Administration (FDA) and the European Medicines Agency (EMA) for treatment of indolent NHL: idelalisib, copanlisib, and duvelisib [45]. Idelalisib is the first-in-class reversible, highly selective inhibitor of delta PI3K isoform, and the most common adverse events are diarrhea, pneumonia and pneumonitis, hepatotoxicity, thrombocytopenia, and skin rash [46,47]. Cardiovascular adverse events are not frequent; however, $\mathrm{AF}$ and peripheral edema can occur. No increase in cumulative incidence of pulmonary hypertension, QT prolongation, or PAD has been reported [48]. Idelalisib and duvelisib have a safer cardiovascular profile compared to copanlisib, a pan-class PI3K inhibitor of $\alpha$ and $\delta$ isoforms, which frequently cause infusion-related hyperglycemia and hypertension $(57.1 \%$ and $54.8 \%$, respectively), as well as diarrhea [49,50]. Hypertension usually develops within $2 \mathrm{~h}$ of the first cycle infusion with a mean systolic BP increase of $16.8 \mathrm{mmHg}$, and resolves within $24 \mathrm{~h} \mathrm{[51].}$

\subsection{Isocitrate Dehydrogenase (IDH) Inhibitors}

IDH1 and IDH2 catalyze oxidative decarboxylation of isocitrate to $\alpha$-ketoglutarate $(\alpha \mathrm{KG})$ and $\mathrm{CO}_{2}$. Under physiological conditions, D-2-hydroxyglutarate (D2HG) is rapidly converted in $\alpha \mathrm{KG}$ by an endogenous D2HG dehydrogenase enzyme [52]; when somatic mutations occur in IDH1 and $I D H 2$, mutant forms acquire a neo-morphic activity causing reduction of $\alpha \mathrm{KG}$ to the oncometabolite 
R-2-hydroxyglutarate that competitively inhibits the endogenous D2HG dehydrogenase enzyme. The modifications lead to an intracellular accumulation of D2HG, epigenetic alterations, and impaired hematopoietic differentiation [52,53]. Ivosidenib, a mutant IDH1 inhibitor, and enasidenib, a mutant IDH2 inhibitor, have been approved for treatment of relapsed/refractory acute myeloid leukemia (AML). QT prolongation is a common cardiotoxicity during ivosidenib treatment with an incidence of $24.6 \%$ at starting dose of $500 \mathrm{mg}$ daily, and $10.1 \%$ of those adverse events are of grade 3 or higher [53]. Recently, a case of myopericarditis and cardiogenic shock following an IDH inhibitor-induced differentiation syndrome (IDH-DS) has been reported during enasidenib treatment [54-56]. IDH2 inhibitor can also cause QT prolongation [57].

\subsection{Janus Kinase Inhibitor}

Janus kinases (JAKs) are a family of tyrosine kinases widely involved in signaling transduction [58]. In myeloproliferative disorders (MPNs), increased activation of JAK/STAT pathways in hematopoietic stem cells (HSCs) causes uncontrolled proliferation and cytokine production [59,60]; however, hematopoiesis is not ineffective as in myelodysplastic syndromes (MDS), and patients show various grades of polycythemia and/or thrombocytosis, and extramedullary hematopoiesis with splenomegaly [60]. The three most common molecular alterations are a somatic $\mathrm{G}>\mathrm{T}$ mutation in position 1849 of exon 14 of the Janus Kinase 2 (JAK2) with valine to phenylalanine substitution in codon 617 (V617F); a W>L/K/A substitution in exon 10, codon 10 of the thrombopoietin receptor (MPL) gene; and mutations in exon 9 of the calreticulin (CALR) gene as a 52-bp deletion (L367fs*46) or a 5-bp insertion (K385fs*47) [61].

In 2011, the first JAK1/2 inhibitor, ruxolitinib, was approved for treatment of primary and secondary myelofibrosis (COMFORT studies) [62], and in 2014 and 2019, also for treatment of polycythemia vera (PV) and acute graft versus host disease (GvHD) [63,64]. Ruxolitinib-associated cardiotoxicity is still not well characterized; however, arterial hypertension might be a frequent comorbidity, as systolic BP can significantly increase after 72 weeks of treatment without significant changes in diastolic BP [65]. Patients can experience a worsening of pre-existing hypertension or can either develop a new onset disease (from $64.7 \%$ at baseline to $69.1 \%$ after 72 weeks of treatment) [65]. Ruxolitinib can attenuate the effects of growth hormones on STAT5 phosphorylation and favor weight gain through inhibition of JAK/STAT signaling in adipose tissue contributing to hypertension development and probably to late-onset cardiovascular diseases (Figure 2) [65]. After 72 weeks of treatment, the proportion of obese patients can double, and about $21 \%$ of subjects moves up to a higher BMI class [65]. No electrocardiographic changes have been reported [66]. A case of pulmonary hypertension with left ventricular (LV) dysfunction after five years of ruxolitinib treatment has been recently reported [67].

Fedratinib, an oral, potent JAK2 inhibitor effective against wild-type and mutationally activated JAK2 and fms-like tyrosine kinase 3 (FLT3), was approved in 2019 for treatment of adult patients with intermediate-2 or high-risk primary or secondary myelofibrosis [68]. Cardiotoxicity of fedratinib is still under investigation; however, peripheral edema and HF are reported [69,70]. However, fedratinib has received a "black-box warning" because of the increased risk of fatal encephalopathy including Wernicke encephalopathy [71]. Other JAK inhibitors under investigation are momelotinib and the dual JAK/FLT3 inhibitor pacritinib that cause less hematological adverse events and cardiotoxicity [72].

\section{5. $B C R / A B L$ Inhibitors}

All known BCR/ABL fusion protein variants are composed by an ABL tyrosine kinase domain constitutionally active downstream of various signaling pathways, such as PI3K and STAT, involved in gene expression, mRNA processing and maturation, and protein stability [73,74]. In HSC compartment, deregulation of these pathways translates in increased cell survival and proliferation, and impaired differentiation with suppression of granulocyte maturation [74]. Imatinib, the first-in-class oral TKI approved for treatment of CML in 2001, has pharmacological activity against ABL, BCR/ABL, 
platelet-derived growth factor receptor A (PDGFRA), and c-KIT on neoplastic cells, and also against ABL on normal cells [73]. Imatinib binds amino acid residues in the ATP binding site and stabilizes the inactive forms preventing autophosphorylation and thus switching off signaling transduction [74]. Because of its off-target effects, imatinib can cause different adverse events, including cardiotoxicity [75]. CML patients can develop CHF with New York Heart Association (NYHA) class 3-4 symptoms after a mean of $7.2 \pm 5.4$ months of treatment [75]. Those findings opened a controversial debate on imatinib safety and related cardiotoxicity, as discordant data have been reported during last decades, especially from small case series [76-80]. Although rare, CHF and LVEF depression might occur with an incidence of $0.7-1.8 \%$ after a long-course imatinib treatment (6 months or more) in older patients [80-83].

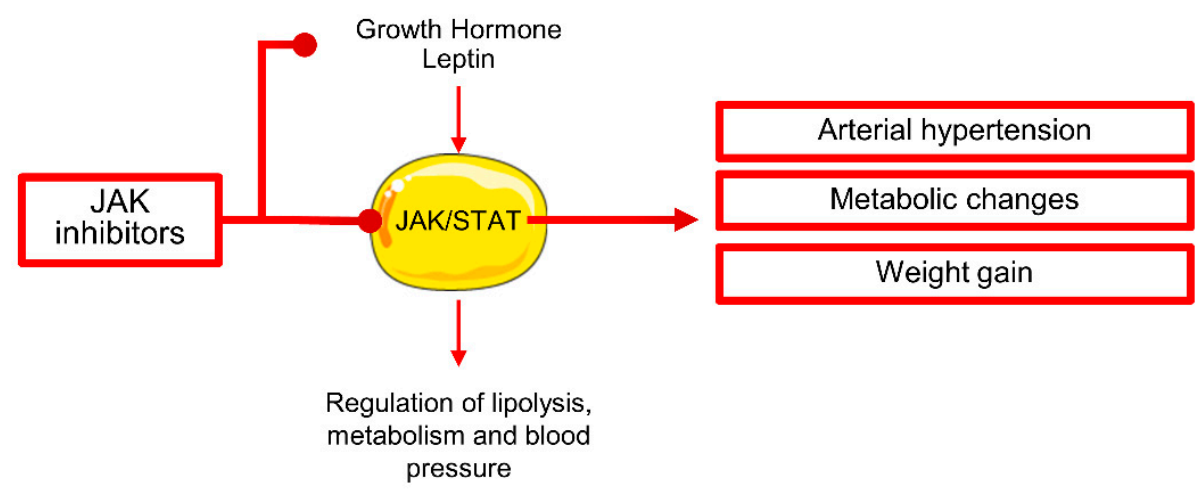

Figure 2. Cardiotoxicity of Janus kinase (JAK) inhibitors. JAK inhibitors can interfere with growth hormone and leptin pathways in adipocytes, causing dysregulation of lipolysis, metabolism, and blood pressure homeostasis. In adipocytes, JAK/signal transducer and activator of transcription (STAT) pathway, mainly through STAT5, is involved in regulation of lipolysis, glucose and lipid metabolism, response to insulin stimulation, and regulation of blood pressure. Inhibition of JAK/STAT in adipocytes can contribute to metabolic changes leading to weight gain and arterial hypertension development.

Dasatinib, a second-generation TKI, can similarly induce CHF, with a reported incidence of $2-4 \%$ [80,83-85]. Other types of cardiotoxicity are arrhythmias, asymptomatic QT prolongation, and pleural and pericardial effusion [80]. Dasatinib administration at $140 \mathrm{mg} /$ daily has been associated with increased incidence of pleural effusion in up to $35 \%$ of cases, higher in those subjects with CML in accelerated and blast phase [86,87]. Pleural and pericardial effusion has been also reported at lower dose (100 mg or $50 \mathrm{mg}$ daily) [88], while single daily dose administration might decrease pleural effusion rate within the first 12 months of treatment $[89,90]$. Risk factors are history of cardiac disease, hypertension, and use of dasatinib at twice-daily schedule [88].

Nilotinib, a second-generation TKI, is 30 -fold more potent than imatinib in blocking BCR/ABL activity; however, this drug is one of the most cardiotoxic TKIs. The most frequent cardiac adverse event is dose-dependent QT prolongation and sudden cardiac death $[83,84,91]$. Nilotinib-associated arrhythmias are caused by off-target inhibitory effects on a potassium ion channel (Kv11.1) involved in delayed-rectifier $\mathrm{K}^{+}$current in cardiac tissue, thus inducing QT wave alterations (Figure 3A) [91]. In addition, MI, acute coronary disease (ACS), and peripheral arterial occlusive disease (PAOD) are frequent, with incidence varying among studies [84]. Nilotinib has additional off-target effects on vascular tissue and pro-atherogenic activities causing arterial stenosis and vasospasm. Moreover, nilotinib induces metabolic modifications, such as increased cholesterol and glucose levels, contributing to increased cardiovascular risk [92,93], and has a direct cardiotoxic effect through caspase activation and apoptosis induction [94]. Median time to a cardiovascular event is 14.5 months (range, 2-68), and patients might experience recurrent diseases requiring several angioplasties and/or surgeries within a few months $[95,96]$. 


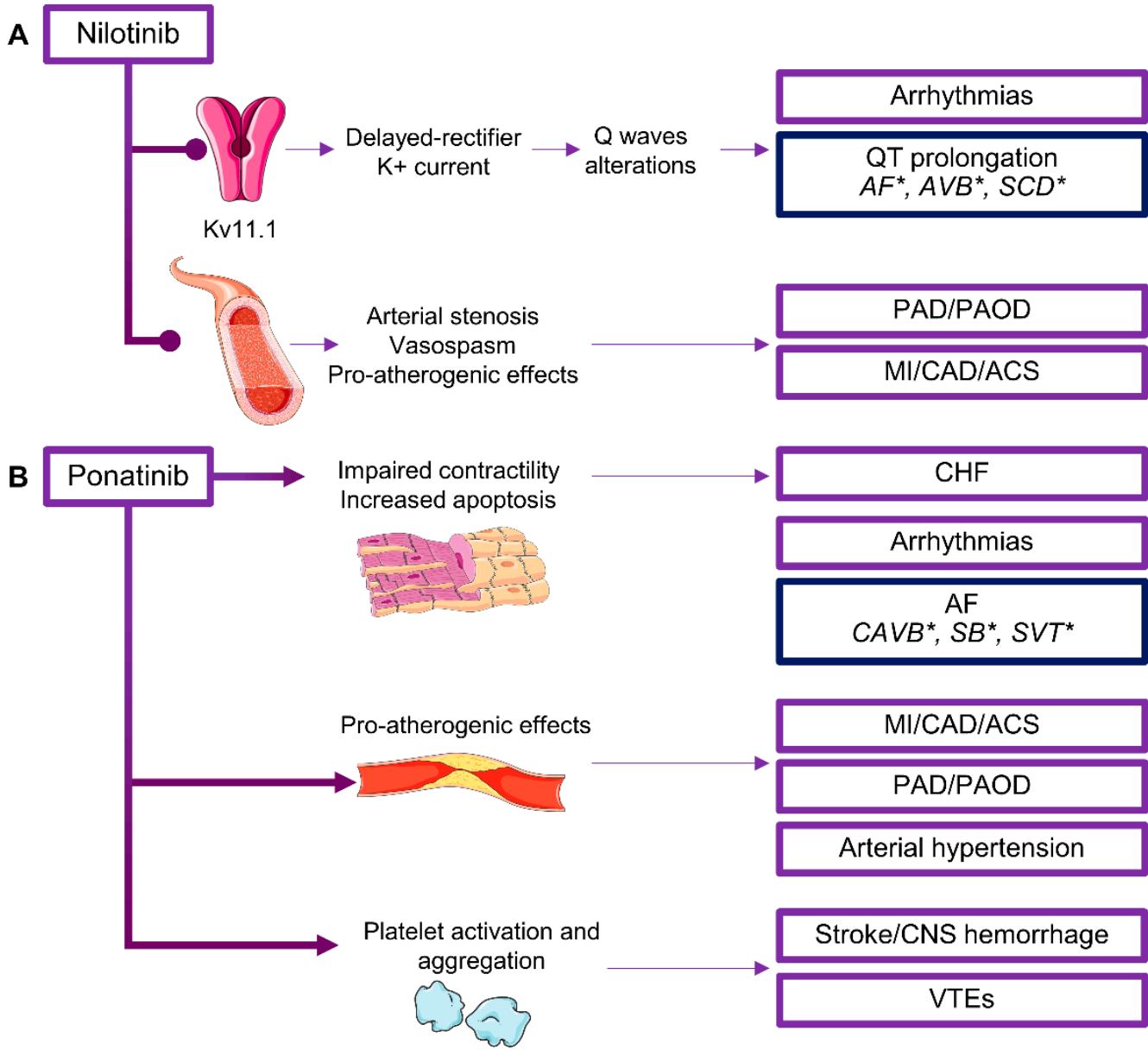

Figure 3. Cardiotoxicity of B cell receptor (BCR)/ABL tyrosine kinase inhibitors (TKIs). Cardiotoxicity of (A) nilotinib and (B) ponatinib. Inhibitors of BCR/ABL activity cause various forms of cardiotoxicity, such as congestive heart failure (CHF), myocardial infarction (MI), acute coronary syndrome (ACS), coronary artery disease (CAD), peripheral artery disease (PAD), peripheral arterial occlusive disease (PAOD), venous thromboembolisms (VTEs), and arrhythmias. SCD, sudden cardiac death; SVT, supraventricular tachycardia; CAVB, complete atrioventricular block; SB, sinus bradycardia.

* Uncommon and rare cardiotoxicity (frequency $<1 \%$ or case reports).

Bosutinib, a second-generation TKI active against SRC/ABL, has been approved for CML resistant or intolerant to prior TKI therapy [97]. Bosutinib-associated cardiotoxicity incidence is low (6.8\%); however, refractory/relapsed CML patients who received bosutinib as second- or above-line therapy have an increased incidence of cardiac adverse events compared to those who received bosutinib as first-line therapy (7.7\% vs. $4.8 \%$, respectively), especially cerebrovascular events [97]. Among cardiotoxic manifestations, angina pectoris, CAD, and PAD are frequent $(1.2 \%, 1.2 \%$, and $2 \%$, respectively), while aortic arteriosclerosis, peripheral coldness, venous insufficiency, deep vein thrombosis, Raynaud's phenomenon, and PAOD are uncommon. Serious adverse events are more frequently represented by CAD and MI, while deaths are often caused by cerebrovascular accidents in younger patients, or cardiovascular events in older subjects. Patients with advanced disease or receiving bosutinib as second- or above-line therapy have a greater risk of serious events and death [97]. Hypertension can occur in $7.8 \%$ of cases, especially those with a history of hypertension; however, incidence is similar to that of CML subjects treated with other TKIs, such as imatinib [97]. Age $\geq 65$ years is a risk factor of cardiotoxicity when bosutinib is administered as firstor above-line treatment, while Eastern Cooperative Oncology Group performance status (ECOG PS) $>0$, pre-existing cardiovascular disorders and/or diabetes, and history of hyperlipidemia/increased cholesterol 
are risk factors when bosutinib is administered as second- or above-line treatment [97]. Other reported cardiotoxicity is peripheral edema, CHF, AF, QT prolongation, and pericardial effusion [98].

Ponatinib, a third-generation TKI, shows activity against multiple kinases, such as SRC/ABL, fibroblast growth factor receptor 1 (FGFR1), PDGFRA, vascular endothelial growth factor receptor 2 (VEGFR2), c-KIT, and FLT3 in hematopoietic cells, as well as FGFR2/3/4 and RET in various tumors [99]. Ponatinib has been approved for $\mathrm{CML}$ and $\mathrm{Ph}$-positive $(\mathrm{Ph}+)$ acute lymphoblastic leukemia (ALL) resistant or intolerant to prior TKI therapy or for patients carrying the point mutation threonine to isoleucine at codon 315 (T315I) in BCR/ABL1 kinase domain, a frequent somatic mutation associated with resistance to first- and second-generation TKIs [100]. Despite its efficacy, ponatinib is one of the most cardiotoxic TKIs, causing CHF, arrhythmias, arterial occlusive events, and hypertension [101-103]. Mechanisms of cardiotoxicity are still under investigation; however, off-target effects, especially on PI3K and Akt signaling pathways, could induce cardiotoxicity (Figure 3B) [101]. Off-target FGFR inhibition causes modifications in in vitro proliferation and differentiation of cardiomyocytes; FLT3 and c-Jun blockade is related to apoptosis; while PDGFR, VEGFR, and c-Src inhibition induces contractile alterations [101]. In addition, ponatinib can have pro-atherogenic properties by promoting surface adhesion receptor expression, and by enhancing platelet activation and aggregation [101]. Cumulative incidence of CAD, PAD, and cerebrovascular events is $26 \%[101,104,105]$. In chronic phase CML, ACS and MI are the most frequent manifestations ( $12 \%$ of cases) and can precede CHF with a median time to initial onset of 11.5 months; cerebrovascular and peripheral arterial occlusive events occur in $6 \%$ and $8 \%$ of cases, respectively, and venous thromboembolic events (VTEs) are reported in 5\% of subjects [101,104,105]. Hypertension is also frequent (14\%). Serious cardiac adverse events are represented by $\mathrm{AF}(6 \%)$ and angina pectoris $(5 \%)$ [104]. Incidence of cardiotoxicity is related to dose intensity with the highest rate (42\%) at $45 \mathrm{mg} /$ daily. History of ischemia, age at study entry, baseline neutrophil count, and time to treatment are prognostic risk factors [103]. In addition, there might be a lag time between drug administration and onset of cardiovascular event, as $7 \%$ of patients experience cardiotoxicity after study discontinuation [103,104]. Cardiovascular events can occur in $7.1 \%$ of patients, cerebrovascular accidents in $3.6 \%$, and peripheral vascular events in $4.9 \%$ of subjects, more frequently in patients with a history of cardiovascular diseases and/or the presence of one or more cardiovascular risk factors, such as hypertension, diabetes, hypercholesterolemia, and obesity [105]. Moreover, ponatinib-treated patients have an increased incidence of recurrent arterial occlusive events compared to those treated with dasatinib or bosutinib (76.7\% vs. $64 \%$, respectively) [106]. Risk stratification can be assessed using a clinical score (Systematic Coronary Risk Evaluation (SCORE)) based on sex, age, smoking status, systolic BP, and total cholesterol levels. Patients with SCORE $>5 \%$ have a higher incidence of arterial occlusive events compared to those subjects with SCORE $<5 \%$ (74.3\% vs. 15.2\%) [107]. Aspirin administration can lower cardiovascular risk, especially in patients aged $>60$ years [107].

\subsection{Other TKIs}

Gilteritinib is a novel FLT3 inhibitor approved in 2019 as a monotherapy for relapsed/refractory AML harboring FLT3 mutations including internal tandem duplication (ITD), D835Y, or D835Y somatic mutations. FLT3 blockade induces apoptosis in leukemic cells that rely on FLT3 signaling pathway for survival [108]. The most frequent reported cardiotoxicity is peripheral edema (any grade, 24\%), and QT prolongation (4.9\%) requiring dose reduction; however, QTc interval $>500 \mathrm{~ms}$ is uncommon (0.4\%) [109]. Similarly, glasdegib, a selective oral inhibitor of Hedgehog signaling through Smoothened, can also rarely cause QT prolongation $[110,111]$. In contrast with gilteritinib-associated cardiotoxicity, midostaurin does not induce QT prolongation [112]. Midostaurin, a multi-target TKI, shows activity against protein kinase $C$ (PKC), PDGFR $\alpha / \beta$, cyclin-dependent kinase 1 (CDK1), SRC, Syk, c-KIT, VEGFR2, and FLT3 [102,113]. Midostaurin can block autophosphorylation of the endogenous wild-type FLT3, but also both ITD and D835Y forms [113,114]. Other reported cardiotoxicity is hypertension, pericardial effusion, and anecdotic interstitial lung injury with pulmonary hypertension [115]. 


\section{Proteasome Inhibitors}

Poly-ubiquitination is a tag-system used for identification of proteins that need to be degraded because they are redundant, misfolded, or unwanted, such as proteins involved in specific cell cycle phases [116]. Ubiquitinated proteins are then degraded by the 26S proteasome complex hyperactivated in multiple myeloma (MM) causing excessive intracellular removal of important proteins, such as tumor suppressor p53 and IкB (inhibitor of nuclear factor- $\mathrm{kB}(\mathrm{NF}-\mathrm{\kappa} B)$ ). This alteration in proteasome activity translates in the deregulation of several intracellular processes, including cell cycle and apoptosis control, pro-inflammatory cytokine signaling, and stress response, leading to increased survival and proliferation of neoplastic clones [116]. Therefore, specific inhibitors can block oncogenic progression by interfering with constitutive and immune proteasome activity. These two forms of proteasomes differ for the barrel-like structure composition of the 20S catalytic domain-the constitutive form is composed of $\beta 5, \beta 1$, and $\beta 2$ subunits, while the immunoproteasome $20 \mathrm{~S}$ core has the $\beta 5 \mathrm{i}, \beta 1 \mathrm{i}$, and $\beta 2 \mathrm{i}$ subunits, whose expression is regulated by pro-inflammatory cytokines [116].

Bortezomib, the first-in-class proteasome inhibitor, shows activity against the $\beta 5, \beta 1$, and $\beta 5 \mathrm{i}$ subunits, thus interfering with both constitutive and immune proteasome forms. Proteasome is important in protein homeostasis maintenance in tissues with high metabolic demand, such as cardiac and liver tissues, and inhibition might cause cardiomyocyte disfunction and HF [117]. In rats, bortezomib can induce left ventricular contractile dysfunction with mitochondrial modifications, and reduction in ATP synthesis and cardiomyocyte contractile functions [118]. In clinical trials, incidence of bortezomib-associated cardiotoxicity varies from $0 \%$ to $17.9 \%$, with the highest incidence in elderly patients with MCL and in MM subjects receiving bortezomib as monotherapy; however, the risk of cardiotoxicity is not higher than that of patients treated with other chemotherapeutic drugs [119]. The most common cardiotoxicity is CHF $(2-5 \%)$, particularly frequent in patients aged $>70$ years and after a median of 3.2 months after starting bortezomib [120]; cardiomyopathy; acute MI; and arrhythmias. Hospitalization rate for CHF is 5.76/100 PY, for acute MI is 2.57/100 PY, and for arrhythmias is 3.10/100 PY [121,122]. Complete heart block and acute left ventricular dysfunction have also been described in few case reports [123-127]. Arrhythmias are secondary to HF, and case reports show various manifestations, including $\mathrm{AF}$, complete atrio-ventricular block (CAVB), premature atrial or ventricular complexes (PAC and PVC), sinus bradycardia or tachycardia (SB and ST), supraventricular or ventricular tachycardia (SVT and VT), and torsades de pointes [128].

Carfilzomib, a second-generation proteasome inhibitor, has a cardiotoxic activity similar to that of bortezomib, with carfilzomib-associated cardiac event rate of $27 \%$ vs. $16 \%$ of bortezomib-treated patients and similar cumulative incidences [126,129]. More than $7 \%$ of patients can experience CHF, pulmonary edema, or decreased ejection fraction with an overall mortality rate of 7\% [130]. Hypertension is also frequent $(14.3 \%)$, either new onset or worsening of pre-existing conditions. Cardiac adverse events usually occur after a median of 67.5 days of therapy and incidence rate remains similar during treatment duration $[129,130]$. The association of carfilzomib with dexamethasone does not increase frequency of hypertension and HF [131]. In addition, carfilzomib can frequently cause SVT; case reports have described SB, CAVB, PAC, AF, and sudden cardiac death [128]. Ixazomib, the first oral proteasome inhibitor, shows cardiotoxic effects not increasing in combination with lenalidomide; in particular, ixazomib can induce arrhythmias, hypertension, HF, and MI [116]. However, MM patients are frequently old and frail with high incidence of pre-existing cardiac and renal diseases or MM-associated comorbidities that negatively decrease cardiac functions and general status, which is a great bias when analyzing safety cardiovascular profile of novel drugs for MM treatment [123,132]. In addition, association of proteasome inhibitors with other cardiotoxic drugs, such as lenalidomide, which are the standard of care is another limitation in assessment of cardiac safety profile of this class of drugs. Finally, new therapies are investigated on heavily pre-treated patients, and, in the case of MM, previous treatments are highly cardiotoxic; therefore, a novel drug is often administered to a subject with an already reduced cardiac function or with other treatment-related cardiovascular diseases $[123,126]$. 


\section{IMiDs}

IMiDs are a milestone in MM treatment. Neoplastic plasma cells finely interact with the BM microenvironment to increase their survival and to escape from immunosurveillance. IMiDs can interfere with pro-survival and anti-apoptotic pathways in malignant plasma cells, and with microenvironment interactions $[133,134]$. Thalidomide, the first-in-class IMiD, has anti-angiogenic and anti-tumor necrosis factor (TNF) activities; the two synthetic analogues, lenalidomide and pomalidomide, also modulate $\mathrm{T}$ cell differentiation by increasing the frequency of central and effector memory CD8 ${ }^{+} \mathrm{T}$ cells, $\mathrm{T}$ regulatory cells (Tregs), natural killer (NK) and NKT cells, and myeloid derived suppressor cells, while decreasing effector terminally differentiated $\mathrm{T}$ cells and expression of co-inhibitory receptors $[133,134]$.

The most common cardiotoxicity of IMiDs are arrhythmias, venous thromboembolism (VTE), myocardial infarction, and cerebrovascular events [132,135-139]. Thalidomide is frequently associated with SB and AF, while CAVB, SVT, PVC, VT, and sudden cardiac death are rarely reported [128]; lenalidomide can cause $\mathrm{AF}$, while $\mathrm{SB}, \mathrm{SVT}, \mathrm{VT}$, and sudden cardiac death are infrequent [128]; and pomalidomide is associated with AF [139]. Lenalidomide can cause new onset HF (1.22 events per 100 PY) or worsen a pre-existing condition (9.76 events per 100 PY) [137]. Results from the ASPIRE trial using lenalidomide plus dexamethasone with or without carfilzomib show that lenalidomide alone increases the incidence of hypertension, HF, ischemic HF, and dyspnea [132]. Arterial and venous thromboembolisms are frequent, and incidence increases when IMiDs are associated with proteasome inhibitors or other chemotherapeutic agents [139]. Thalidomide and lenalidomide alone are associated with thrombotic events in up to $26 \%$ of patients, while pomalidomide is associated with up to 5\% [139-141]. Age and active uncontrolled disease are risk factors of VTE [135]; however, MM patients themselves have an increased risk of VTE compared to other cancer subjects because of the presence of a hypercoagulable status that leads to VTE in $10 \%$ of cases receiving standard chemotherapy [138]. Lenalidomide is also associated with increased risk of arterial thromboembolism with incidence of myocardial infarction of $1.98 \%$ and cerebrovascular accidents of $3.4 \%$ [138]. For this reason, lenalidomide has a "black box warning" for arterial thromboembolism events.

\section{Demethylating Agents}

Modifications in DNA methylation are frequent in solid tumors and hematological diseases and are related to aberrations in gene expression and genomic instability, leading to increased gene mutations and chromosomal abnormalities. Azacytidine and decitabine are the two demethylating agents approved for the treatment of MDS and AML because of their ability to inhibit DNA methylation and induce cell differentiation, thus reducing ineffective hemopoiesis occurring during MDS and AML [142]. Phase II clinical trials have shown efficacy and safety of these drugs in elderly patients, without a significant increase of cardiac adverse event rates despite the older age of subjects and the presence of several comorbidities [143]. However, HF can frequently occur in up to $25 \%$ of elderly patients (mean age, 77.3 years) with MDS after a mean of 7.4 cycles, and history of cardiac diseases, red blood cell transfusion dependency, and increased levels of WT-1 are proposed as risk factors for HF during demethylating agent treatment [143]. Sporadic cases of pericarditis and cardiomyopathy are reported [144,145].

\section{Monoclonal Antibodies}

Monoclonal antibodies (MoAbs) are designed to recognize and bind tumor-specific antigens and direct against malignant cells through three types of immune responses resulting in tumor cell killing: antibody-dependent cell-mediated cytotoxicity (ADCC), complement-dependent cytotoxicity (CDC), and antibody-dependent phagocytosis (ADCP) [146]. In addition, MoAbs can bind receptors or molecules and interfere with specific signaling pathways, such as checkpoint inhibitors that bind PD-1 and stop its inhibitory signals in T cells [147]. In hematology, physiological expression of surface 
and intracellular markers in hematopoietic stem and progenitor cell compartment and in mature cells is well known, as well as neoplastic cell immunophenotype, which is characterized by the aberrant expression of lineage-specific antigens [148]. Therefore, malignant cells can be easily identified and targeted by specific MoAbs. In B cell non-Hodgkin lymphomas (NHL), neoplastic cells frequently show positivity for the CD20 antigen, a proposed calcium channel, which expression is normally lost on mature $B$ cells, plasma blasts, and plasma cells. MoAbs direct against CD20 have radically changed clinical outcomes of B cell NHL, as neoplastic cells can be specifically targeted by those MoAbs and killed through ADCC or CDC mechanisms. Rituximab is a murine-human chimeric first-generation anti-CD20 MoAb, while obinutuzumab and ofatumumab are second-generation humanized or fully human anti-CD20 MoAbs that are less immunogenic and more effective in inducing apoptosis in B cells compared to rituximab $[149,150]$. MoAbs and their cardiotoxic effects are summarized in Table 1, showing that infusion-related reactions, hypertension or hypotension, and arrhythmias are the most common cardiotoxicity.

Table 1. Cardiotoxicity of monoclonal antibodies (MoAbs) in hematology.

\begin{tabular}{|c|c|c|c|}
\hline MoAb & Target & Indications & Cardiotoxicity \\
\hline Rituximab & CD20 & NHL CLL & $\begin{array}{c}\text { IRRs } \\
\text { Hypertension }(6-12 \%) \\
\text { Transient hypotension }(10 \%) \\
\text { SVT, AF } \\
\text { Takotsubo * } \\
\mathrm{CAVB}^{*}, \mathrm{ST}^{*}, \mathrm{SB}^{*}, \mathrm{PVC}^{*}, \mathrm{VT}^{*}, \mathrm{QTc} / \mathrm{TdP}^{*}, \mathrm{SCD}^{*}\end{array}$ \\
\hline Obinutuzumab & CD20 & $\mathrm{CLL} / \mathrm{FL}$ & IRRs, $\mathrm{SCD}^{*}, \mathrm{HF}^{*}$ \\
\hline Ofatumumab & CD20 & CLL & $\begin{array}{c}\text { IRRs } \\
\text { Hypertension/hypotension } \\
\text { Tachycardia } \\
\mathrm{AF}^{*}, \mathrm{HF}^{*}, \mathrm{MI}^{*} \text {, pericarditis * }\end{array}$ \\
\hline Daratumumab & CD38 & $\mathrm{MM}$ & $\begin{array}{c}\text { IRRs } \\
\text { Hypertension } \\
\text { AF } \\
\text { SCD }^{*}\end{array}$ \\
\hline Isatuximab & CD38 & $\mathrm{MM}$ & $\begin{array}{l}\text { IRRs } \\
\text { AF }\end{array}$ \\
\hline Elotuzumab & SLAMF7 & MM & $\begin{array}{l}\text { IRRs } \\
\text { DVT }\end{array}$ \\
\hline Brentuximab vedotin & CD30 & HL & $\begin{array}{c}\mathrm{ST}(6 \%) \\
\text { Pericardial effusion }(3 \%) \\
\mathrm{CHF}^{*}, \mathrm{MI}^{*}\end{array}$ \\
\hline Nivolumab & PD-1 & HL & $\begin{array}{c}\text { Myocarditis } \\
\text { Pericardial diseases } \\
\text { Stress cardiomyopathy } \\
\text { VT } \\
\text { CAVB *,SCD * }\end{array}$ \\
\hline Pembrolizumab & PD-1 & HL & $\begin{array}{c}\text { Myocarditis } \\
\text { Pericardial diseases } \\
\text { Stress cardiomyopathy } \\
\mathrm{ST}^{*}, \mathrm{AF}^{*}, \mathrm{PVC}^{*}, \mathrm{VT}^{*}, \mathrm{SCD}^{*}\end{array}$ \\
\hline Gemtuzumab ozogamicin & CD33 & AML & $\begin{array}{c}\text { VOD }(2 \%) \\
\text { Tachycardia, ST, SVT (13\%) } \\
\text { Hypertension }(17.3 \%)\end{array}$ \\
\hline Blinatumomab & CD19/CD3 & R/R Ph-ALL & $\begin{array}{c}\text { Tachycardia } \\
\text { HF }^{*}\end{array}$ \\
\hline Belantamab mafodotin & BCMA & MM & Not reported \\
\hline Inotuzumab ozogamicin & CD22 & $\mathrm{Ph}+\mathrm{ALL}$ & $\begin{array}{c}\text { VOD } \\
\text { QT/QTc }\end{array}$ \\
\hline Moxetumomab pasudotox & CD22 & $\mathrm{R} / \mathrm{R} \mathrm{HCL}$ & $\begin{array}{c}\text { HUS * } \\
\text { Pericardial/pleural effusion * } \\
\text { Hypertension/hypotension * } \\
\text { Tachycardia * }\end{array}$ \\
\hline
\end{tabular}


Table 1. Cont.

\begin{tabular}{cccc}
\hline MoAb & Target & Indications & Cardiotoxicity \\
\hline Tafasitamab & CD19 & DLBCL & $\begin{array}{c}\text { Pulmonary embolism }(4 \%) \\
\text { AF }(2 \%) \\
\text { CHF }(2 \%)\end{array}$ \\
\hline Polatuzumab vedotin & CD79a & DLBCL & Hypotension \\
\hline Ravulizumab & C5a & PNH HUS & Hypertension/hypotension * \\
\hline Eculizumab & C5a & PNH HUS & $\begin{array}{c}\text { Hypertension } \\
\text { Tachycardia/Palpitation } \\
\text { Cardiomyopathy } \\
\text { Hypotension * }\end{array}$ \\
\hline Emapalumab & IFN $\gamma$ & R/R HLH & $\begin{array}{c}\text { Hypertension (41\%) } \\
\text { Tachycardia (12\%) } \\
\text { Bradycardia * }\end{array}$ \\
\hline Siltuximab & IL-6 & Castleman disease & $\begin{array}{c}\text { Hypertension } \\
\text { Peripheral edema (26\%) }\end{array}$ \\
\hline
\end{tabular}

Abbreviations: MoAb, monoclonal antibodies; NHL, non-Hodgkin lymphomas; CLL, chronic lymphocytic leukemia; IRRs, infusion-related reactions; SVT, supraventricular tachycardia; AF, atrial fibrillation; CAVB, complete atrioventricular block; ST, sinus tachycardia; SB, sinus bradycardia; PVC, premature ventricular contractions; VT, ventricular tachycardia; QT/QTc, QT interval prolongation; TdP, torsade de pointes; SCD, sudden cardiac death; FL, follicular lymphoma; HF, heart failure; MI, myocardial infarction; MM, multiple myeloma; DVT, deep vein thrombosis; HL, Hodgkin lymphoma; CHF, congestive heart failure; PD-1, programmed cell death protein 1; AML, acute myeloid leukemia; VOD, veno-occlusive disease; R/R, relapsed/refractory; Ph, Philadelphia chromosome; ALL, acute lymphoblastic leukemia; BCMA, B cell maturation antigen; HCL, hairy cell leukemia; HUS, hemolytic uremic syndrome; DLBCL, diffuse large B cell lymphoma; PNH, paroxysmal nocturnal hemoglobinuria; IFN $\gamma$, interferon gamma; HLH, hemophagocytic lymphohistiocytosis; IL-6, interleukin-6. * Uncommon and rare cardiotoxicity (frequency $<1 \%$ or case reports).

MoAbs against CD38, a type II transmembrane glycoprotein with ectoenzymatic activities, are used in MM treatment because neoplastic plasma cells highly express this surface marker [151]. Daratumumab, a fully human MoAb, and isatuximab, a chimeric MoAb recently approved by the FDA, are the two anti-CD38 antibodies used in clinical practice for MM treatment in association with IMiDs, proteasome inhibitors, and steroids [152]. Other promising MoAbs in MM treatment are elotuzumab, an anti-SLAMF7 (or CD319), approved in combination with lenalidomide and dexamethasone in relapsed/refractory MM patients [153], and belantamab mafodotin, an anti-B cell maturating antigen (BCMA) MoAb conjugated with a monomethyl auristatin F, approved as monotherapy in MM patients with disease progression who are refractory to proteasome inhibitors, IMiDs, and anti-CD38 MoAbs [154]. Brentuximab vedotin is an anti-CD30 MoAb conjugated with auristatin $\mathrm{E}$, an anti-microtubule agent, and is currently used in $\mathrm{CD} 30^{+}$lymphoproliferative neoplasmas, such as advanced stage or relapsed/refractory Hodgkin lymphoma (HL), systemic anaplastic large cell lymphoma (ALCL), and CD30 cutaneous $\mathrm{T}$ cell lymphomas $[155,156]$. In addition, two checkpoint inhibitors, the anti-PD-1 nivolumab and pembrolizumab MoAbs, have been approved for classical HL in relapsed/refractory patients after autologous stem cell transplantation or treatment with brentuximab vedotin [157]. Two new MoAbs approved for treatment of relapsed or refractory diffuse large B cell lymphoma (DLBCL) are the anti-CD19 tafasitamab, and the anti-CD79a conjugated with monomethyl auristatin E polatuzumab vedotin [158,159]. The most frequent cardiotoxicity is infusion-related reactions, hypertension, and arrhythmias, such as AF or tachycardia [160]; however, the exact mechanisms of non-infusion-related cardiotoxicity are still under investigation. For checkpoint inhibitors, myocarditis and pericardial diseases can be caused by autoimmune reactions against cardiac tissue triggered by hyperactivation of immune cells [161], while conjugated MoAbs, such brentuximab vedotin, can directly induce cardiotoxicity through off-target effects of coupled cytotoxic agents, such as auristatin $\mathrm{E}$, an anti-mitotic drug.

\section{Conclusions}

Drugs in onco-hematology have both therapeutic benefits and toxicities that can compromise clinical response to treatment, worse management, and compliance of patients, and can dramatically reduce quality of life because of serious and late- or long-term adverse events, such as cardiotoxicity [1]. 
Cardiovascular manifestations can vary in types and time of onset depending on presence of risk factors, gene polymorphisms, anti-cancer drug used and cumulative dose, and presence of pre-existing conditions. The task force for cancer treatments and cardiovascular toxicity of the European Society of Cardiology (ESC) has outlined practice guidelines for prevention and attenuation of cardiovascular complications of cancer therapy [1]. The first action that a medical doctor must take before initiation of anti-cancer drug treatment is identification of cardiovascular risk factors and pre-existing conditions that are risk factors of cardiotoxicity in patients treated with BTK or JAK inhibitors, dasatinib, bosutinib, or ponatinib [1,162]. Additional risk factors of QT prolongation, such as concomitant use of drugs that increase QT intervals, should be identified, as QT prolongation is one of the most common arrhythmias related to the use of BTK and PI3K inhibitors and nilotinib or bosutinib. Patients with pre-existing conditions or risk factors who must start a cardiotoxic therapy should receive an appropriate treatment for their cardiovascular disease using ACE-Is or ARBs, $\beta$-blockers, statins, and aerobic exercise [1]. In some cases, cardioprotective molecules can be employed, such as dexrazoxane or carvedilol, which can significantly reduce troponin levels and diastolic dysfunction $[1,163,164]$. Patients without baseline risk factors and normal LVEF can also benefit from primary preventive pharmacologic treatment [162]. Cumulative dose of known cardiotoxic drugs should be reduced as soon as possible, such as for nilotinib, ponatinib, or FLT3 inhibitors, or a single daily dose should be used for certain drugs, such as dasatinib, in order to reduce the risk of pleural and pericardial effusion [88]. Therefore, cardiotoxicity prevention can be achieved by treating pre-existing conditions, reducing cardiovascular risk, and using cardioprotective agents, while early detection of cardiotoxicity can be realized with a close monitoring of patients with echocardiographic evaluation of cardiac functions and peripheral system, and with blood tests, such as troponin or BNP levels [9]. An even closer monitoring could be performed in old and frail patients who receive BTK inhibitors, bosutinib, ponatinib, IMiDs, or bortezomib, and in those who have long-course treatment with BTK and BCR/ABL inhibitors or bortezomib. Patients could be monitored for cardiotoxicity also after the end of treatment, such as for ponatinib-treated patients who can develop cardiac adverse events after several months of drug discontinuation $[103,104]$.

In conclusion, cardiotoxicity is an increasing and complex problem as novel targeted therapies have several off-target effects negatively influencing cardiovascular functions and structure, thus worsening quality of life of long-term survivors. In addition, literature on cardiotoxicity is constantly changing as follow-up increases for novel drugs and late- and long-term manifestations occur. Hematologists should closely work with specialized cardiologists for a better clinical management of long-term survivors, and also of elderly and frail patients with MM or AML who already have an increased risk of cardiovascular events because of their hematological condition and the presence of several comorbidities.

Author Contributions: V.G., C.V. and C.S. conducted the literature review, and wrote and edited the manuscript. All authors have read and agreed to the published version of the manuscript.

Funding: This research received no external funding.

Acknowledgments: The authors would like to thank Rosa Finelli for her support and careful reading of an earlier version of the manuscript. Some work arts are from https://smart.servier.com/. This research was supported by the Intramural Program of the Department of Medicine, Surgery and Dentistry "Scuola Medica Salernitana", University of Salerno, Salerno, Italy.

Conflicts of Interest: The authors declare no conflict of interest.

\section{References}

1. Zamorano, J.L.; Lancellotti, P.; Rodriguez Muñoz, D.; Aboyans, V.; Asteggiano, R.; Galderisi, M.; Habib, G.; Lenihan, D.J.; Lip, G.Y.H.; Lyon, A.R.; et al. 2016 ESC Position Paper on cancer treatments and cardiovascular toxicity developed under the auspices of the ESC Committee for Practice Guidelines: The Task Force for cancer treatments and cardiovascular toxicity of the European Society of Cardiology (ESC). Eur. Heart J. 2016, 37, 2768-2801. [CrossRef] 
2. Curigliano, G.; Cardinale, D.; Dent, S.; Criscitiello, C.; Aseyev, O.; Lenihan, D.; Cipolla, C.M. Cardiotoxicity of anticancer treatments: Epidemiology, detection, and management. CA Cancer J. Clin. 2016, 66, 309-325. [CrossRef]

3. Feijen, E.A.M.L.; Font-Gonzalez, A.; Van der Pal, H.J.H.; Kok, W.E.M.; Geskus, R.B.; Ronckers, C.M.; Bresters, D.; van Dalen, E.C.; van Dulmen-den Broeder, E.; van den Berg, M.H.; et al. Risk and Temporal Changes of Heart Failure Among 5-Year Childhood Cancer Survivors: A DCOG-LATER Study. J. Am. Heart Assoc. 2019, 8, e009122. [CrossRef]

4. Lenneman, C.G.; Sawyer, D.B. Cardio-Oncology: An Update on Cardiotoxicity of Cancer-Related Treatment. Circ. Res. 2016, 118, 1008-1020. [CrossRef] [PubMed]

5. Han, X.; Zhou, Y.; Liu, W. Precision cardio-oncology: Understanding the cardiotoxicity of cancer therapy. NPJ Precis. Oncol. 2017, 1, 31. [CrossRef] [PubMed]

6. Galderisi, M.; Santoro, C.; Bossone, E.; Mancusi, C. Rationale and proposal for cardio-oncology services in Italy. J. Cardiovasc. Med. 2020. [CrossRef] [PubMed]

7. Santoro, C.; Esposito, R.; Lembo, M.; Sorrentino, R.; De Santo, I.; Luciano, F.; Casciano, O.; Giuliano, M.; De Placido, S.; Trimarco, B.; et al. Strain-oriented strategy for guiding cardioprotection initiation of breast cancer patients experiencing cardiac dysfunction. Eur. Heart J. Cardiovasc. Imaging 2019, 20, 1345-1352. [CrossRef]

8. Linschoten, M.; Teske, A.J.; Cramer, M.J.; van der Wall, E.; Asselbergs, F.W. Chemotherapy-Related Cardiac Dysfunction: A Systematic Review of Genetic Variants Modulating Individual Risk. Circ. Genom. Precis. Med. 2018, 11, e001753. [CrossRef]

9. Michel, L.; Mincu, R.I.; Mahabadi, A.A.; Settelmeier, S.; Al-Rashid, F.; Rassaf, T.; Totzeck, M. Troponins and brain natriuretic peptides for the prediction of cardiotoxicity in cancer patients: A meta-analysis. Eur. J. Heart Fail. 2020, 22, 350-361. [CrossRef]

10. Morandi, P.; Ruffini, P.A.; Benvenuto, G.M.; Raimondi, R.; Fosser, V. Cardiac toxicity of high-dose chemotherapy. Bone Marrow Transplant. 2005, 35, 323-334. [CrossRef]

11. DeVita, V.T., Jr. A selective history of the therapy of Hodgkin's disease. Br. J. Haematol. 2003, 122, 718-727. [CrossRef] [PubMed]

12. Paul, M.K.; Mukhopadhyay, A.K. Tyrosine kinase-Role and significance in Cancer. Int. J. Med. Sci. 2004, 1, 101-115. [CrossRef] [PubMed]

13. Scheijen, B.; Griffin, J.D. Tyrosine kinase oncogenes in normal hematopoiesis and hematological disease. Oncogene 2002, 21, 3314-3333. [CrossRef] [PubMed]

14. Giudice, V.; Mensitieri, F.; Izzo, V.; Filippelli, A.; Selleri, C. Aptamers and Antisense Oligonucleotides for Diagnosis and Treatment of Hematological Diseases. Int. J. Mol. Sci. 2020, 21, 3252. [CrossRef]

15. Ren, R. Mechanisms of BCR-ABL in the pathogenesis of chronic myelogenous leukaemia. Nat. Rev. Cancer 2005, 5, 172-183. [CrossRef]

16. Pal Singh, S.; Dammeijer, F.; Hendriks, R.W. Role of Bruton's tyrosine kinase in B cells and malignancies. Mol. Cancer 2018, 17, 57. [CrossRef]

17. Anderson, J.S.; Teutsch, M.; Dong, Z.; Wortis, H.H. An essential role for Bruton's [corrected] tyrosine kinase in the regulation of B-cell apoptosis. Proc. Natl. Acad. Sci. USA 1996, 93, 10966-10971. [CrossRef]

18. Glassford, J.; Soeiro, I.; Skarell, S.M.; Banerji, L.; Holman, M.; Klaus, G.G.; Kadowaki, T.; Koyasu, S.; Lam, E.W. BCR targets cyclin D2 via Btk and the p85alpha subunit of PI3-K to induce cell cycle progression in primary mouse B cells. Oncogene 2003, 22, 2248-2259. [CrossRef]

19. Spaargaren, M.; Beuling, E.A.; Rurup, M.L.; Meijer, H.P.; Klok, M.D.; Middendorp, S.; Hendriks, R.W.; Pals, S.T. The B cell antigen receptor controls integrin activity through Btk and PLCgamma2. J. Exp. Med. 2003, 198, 1539-1550. [CrossRef]

20. Brachtl, G.; Piñón Hofbauer, J.; Greil, R.; Hartmann, T.N. The pathogenic relevance of the prognostic markers CD38 and CD49d in chronic lymphocytic leukemia. Ann. Hematol. 2014, 93, 361-374. [CrossRef]

21. Elices, M.J.; Osborn, L.; Takada, Y.; Crouse, C.; Luhowskyj, S.; Hemler, M.E.; Lobb, R.R. VCAM-1 on activated endothelium interacts with the leukocyte integrin VLA-4 at a site distinct from the VLA-4/fibronectin binding site. Cell 1990, 60, 577-584. [CrossRef]

22. Osborn, L.; Hession, C.; Tizard, R.; Vassallo, C.; Luhowskyj, S.; Chi-Rosso, G.; Lobb, R. Direct expression cloning of vascular cell adhesion molecule 1 , a cytokine-induced endothelial protein that binds to lymphocytes. Cell 1989, 59, 1203-1211. [CrossRef] 
23. Shanafelt, T.D.; Geyer, S.M.; Kay, N.E. Prognosis at diagnosis: Integrating molecular biologic insights into clinical practice for patients with CLL. Blood 2004, 103, 1202-1210. [CrossRef] [PubMed]

24. Byrd, J.C.; Brown, J.R.; O’Brien, S.; Barrientos, J.C.; Kay, N.E.; Reddy, N.M.; Coutre, S.; Tam, C.S.; Mulligan, S.P.; Jaeger, U.; et al. Ibrutinib versus ofatumumab in previously treated chronic lymphoid leukemia. N. Engl. J. Med. 2014, 371, 213-223. [CrossRef] [PubMed]

25. Yang, T.; Moslehi, J.J.; Roden, D.M. Proarrhythmic effects of ibrutinib, a clinically approved inhibitor of Bruton's tyrosine kinase (BTK) used in cancer therapy (abstr). Circulation 2015, 132, A14587.

26. McMullen, J.R.; Boey, E.J.; Ooi, J.Y.; Seymour, J.F.; Keating, M.J.; Tam, C.S. Ibrutinib increases the risk of atrial fibrillation, potentially through inhibition of cardiac PI3K-Akt signaling. Blood 2014, 124, 3829-3830. [CrossRef]

27. Zhabyeyev, P.; Chen, X.; Vanhaesebroeck, B.; Oudit, G.Y. PI3K $\alpha$ in cardioprotection: Cytoskeleton, late Na+ current, and mechanism of arrhythmias. Channels 2019, 13, 520-532. [CrossRef]

28. Ghigo, A.; Li, M. Phosphoinositide 3-kinase: Friend and foe in cardiovascular disease. Front. Pharmacol. 2015, 6, 169. [CrossRef]

29. Chong, E.; Chang, S.L.; Hsiao, Y.W.; Singhal, R.; Liu, S.H.; Leha, T.; Lin, W.Y.; Hsu, C.P.; Chen, Y.C.; Chen, Y.J.; et al. Resveratrol, a red wine antioxidant, reduces atrial fibrillation susceptibility in the failing heart by PI3K/AKT/eNOS signaling pathway activation. Heart Rhythm. 2015, 12, 1046-1056. [CrossRef]

30. Li, M.; Sala, V.; De Santis, M.C.; Cimino, J.; Cappello, P.; Pianca, N.; Di Bona, A.; Margaria, J.P.; Martini, M.; Lazzarini, E.; et al. Phosphoinositide 3-Kinase Gamma Inhibition Protects From Anthracycline Cardiotoxicity and Reduces Tumor Growth. Circulation 2018, 138, 696-711. [CrossRef]

31. Jiang, L.; Li, L.; Ruan, Y.; Zuo, S.; Wu, X.; Zhao, Q.; Xing, Y.; Zhao, X.; Xia, S.; Bai, R.; et al. Ibrutinib promotes atrial fibrillation by inducing structural remodeling and calcium dysregulation in the atrium. Heart Rhythm. 2019, 16, 1374-1382. [CrossRef] [PubMed]

32. Fradley, M.G.; Gliksman, M.; Emole, J.; Viganego, F.; Rhea, I.; Welter-Frost, A.; Armanious, M.; Lee, D.H.; Walko, C.; Shah, B.; et al. Rates and Risk of Atrial Arrhythmias in Patients Treated With Ibrutinib Compared With Cytotoxic Chemotherapy. Am. J. Cardiol. 2019, 124, 539-544. [CrossRef] [PubMed]

33. Ganatra, S.; Sharma, A.; Shah, S.; Chaudhry, G.M.; Martin, D.T.; Neilan, T.G.; Mahmood, S.S.; Barac, A.; Groarke, J.D.; Hayek, S.S.; et al. Ibrutinib-Associated Atrial Fibrillation. JACC Clin. Electrophysiol. 2018, 4, 1491-1500. [CrossRef] [PubMed]

34. Psaty, B.M.; Manolio, T.A.; Kuller, L.H.; Kronmal, R.A.; Cushman, M.; Fried, L.P.; White, R.; Furberg, C.D.; Rautaharju, P.M. Incidence of and risk factors for atrial fibrillation in older adults. Circulation 1997, 96, 2455-2461. [CrossRef]

35. Brown, J.R.; Moslehi, J.; O’Brien, S.; Ghia, P.; Hillmen, P.; Cymbalista, F.; Shanafelt, T.D.; Fraser, G.; Rule, S.; Kipps, T.J.; et al. Characterization of atrial fibrillation adverse events reported in ibrutinib randomized controlled registration trials. Haematologica 2017, 102, 1796-1805. [CrossRef]

36. Pineda-Gayoso, R.; Alomar, M.; Lee, D.H.; Fradley, M.G. Cardiovascular Toxicities of Bruton's Tyrosine Kinase Inhibitors. Curr. Treat. Options Oncol. 2020, 21, 67. [CrossRef]

37. Lampson, B.L.; Yu, L.; Glynn, R.J.; Barrientos, J.C.; Jacobsen, E.D.; Banerji, V.; Jones, J.A.; Walewska, R.; Savage, K.J.; Michaud, G.F.; et al. Ventricular arrhythmias and sudden death in patients taking ibrutinib. Blood 2017, 129, 2581-2584. [CrossRef]

38. Bernardeschi, P.; Pirrotta, M.T.; Del Rosso, A.; Fontanelli, G.; Milandri, C. Sudden ventricular fibrillation and death during ibrutinib therapy-A case report. Eur. J. Haematol. 2019, 103, 442-443. [CrossRef]

39. Fradley, M.G.; Welter-Frost, A.; Gliksman, M.; Emole, J.; Viganego, F.; Lee, D.H.; Shah, B.; Chavez, J.C.; Pinilla-Ibarz, J.; Schabath, M.B. Electrocardiographic Changes Associated With Ibrutinib Exposure. Cancer Control 2020, 27, 1073274820931808. [CrossRef]

40. Salem, J.E.; Manouchehri, A.; Bretagne, M.; Lebrun-Vignes, B.; Groarke, J.D.; Johnson, D.B.; Yang, T.; Reddy, N.M.; Funck-Brentano, C.; Brown, J.R.; et al. Cardiovascular Toxicities Associated With Ibrutinib. J. Am. Coll. Cardiol. 2019, 74, 1667-1678. [CrossRef]

41. Ahn, I.E. Cardiovascular adverse events of ibrutinib. Blood 2019, 134, 1881-1882. [CrossRef] [PubMed]

42. Dickerson, T.; Wiczer, T.; Waller, A.; Philippon, J.; Porter, K.; Haddad, D.; Guha, A.; Rogers, K.A.; Bhat, S.; Byrd, J.C.; et al. Hypertension and incident cardiovascular events following ibrutinib initiation. Blood 2019, 134, 1919-1928. [CrossRef] [PubMed] 
43. Caldeira, D.; Alves, D.; Costa, J.; Ferreira, J.J.; Pinto, F.J. Ibrutinib increases the risk of hypertension and atrial fibrillation: Systematic review and meta-analysis. PLoS ONE 2019, 14, e0211228. [CrossRef] [PubMed]

44. Roeker, L.E.; Sarraf Yazdy, M.; Rhodes, J.; Goodfriend, J.; Narkhede, M.; Carver, J.; Mato, A. Hypertension in Patients Treated With Ibrutinib for Chronic Lymphocytic Leukemia. JAMA Netw. Open 2019, 2, e1916326. [CrossRef] [PubMed]

45. Busygina, K.; Jamasbi, J.; Seiler, T.; Deckmyn, H.; Weber, C.; Brandl, R.; Lorenz, R.; Siess, W. Oral Bruton tyrosine kinase inhibitors selectively block atherosclerotic plaque-triggered thrombus formation in humans. Blood 2018, 131, 2605-2616. [CrossRef] [PubMed]

46. Barrientos, J.C. Idelalisib for the treatment of indolent non-Hodgkin lymphoma: A review of its clinical potential. Onco Targets Ther. 2016, 9, 2945-2953. [CrossRef] [PubMed]

47. Sapon-Cousineau, V.; Sapon-Cousineau, S.; Assouline, S. PI3K Inhibitors and Their Role as Novel Agents for Targeted Therapy in Lymphoma. Curr. Treat. Options Oncol. 2020, 21, 51. [CrossRef]

48. de Weerdt, I.; Koopmans, S.M.; Kater, A.P.; van Gelder, M. Incidence and management of toxicity associated with ibrutinib and idelalisib: A practical approach. Haematologica 2017, 102, 1629-1639. [CrossRef]

49. Nair, K.S.; Cheson, B. The role of idelalisib in the treatment of relapsed and refractory chronic lymphocytic leukemia. Ther. Adv. Hematol. 2016, 7, 69-84. [CrossRef]

50. Mahida, H.; Gharia, B.; Ugoeke, N.; Maludum, O.; Asif, A.; Calderon, D. Abstract 11835: Evaluation of Cardiovascular Adverse Events Associated With Ibrutinib; Venetoclax and Idelalisib Used in Treatment of Chronic Lymphocytic Leukemia. Circulation 2018, 138, A11835.

51. Dreyling, M.; Morschhauser, F.; Bouabdallah, K.; Bron, D.; Cunningham, D.; Assouline, S.E.; Verhoef, G.; Linton, K.; Thieblemont, C.; Vitolo, U.; et al. Phase II study of copanlisib; a PI3K inhibitor; in relapsed or refractory; indolent or aggressive lymphoma. Ann. Oncol. 2017, 28, 2169-2178. [CrossRef] [PubMed]

52. Cheson, B.D.; O’Brien, S.; Ewer, M.S.; Goncalves, M.D.; Farooki, A.; Lenz, G.; Yu, A.; Fisher, R.I.; Zinzani, P.L.; Dreyling, M. Optimal Management of Adverse Events From Copanlisib in the Treatment of Patients With Non-Hodgkin Lymphomas. Clin. Lymphoma Myeloma Leuk. 2019, 19, 135-141. [CrossRef] [PubMed]

53. Patnaik, A.; Appleman, L.J.; Tolcher, A.W.; Papadopoulos, K.P.; Beeram, M.; Rasco, D.W.; Weiss, G.J.; Sachdev, J.C.; Chadha, M.; Fulk, M.; et al. First-in-human phase I study of copanlisib (BAY 80-6946), an intravenous pan-class I phosphatidylinositol 3-kinase inhibitor, in patients with advanced solid tumors and non-Hodgkin's lymphomas. Ann. Oncol. 2016, 27, 1928-1940. [CrossRef] [PubMed]

54. Waitkus, M.S.; Diplas, B.H.; Yan, H. Biological Role and Therapeutic Potential of IDH Mutations in Cancer. Cancer Cell. 2018, 34, 186-195. [CrossRef] [PubMed]

55. DiNardo, C.D.; Stein, E.M.; de Botton, S.; Roboz, G.J.; Altman, J.K.; Mims, A.S.; Swords, R.; Collins, R.H.; Mannis, G.N.; Pollyea, D.A.; et al. Durable Remissions with Ivosidenib in IDH1-Mutated Relapsed or Refractory AML. N. Engl. J. Med. 2018, 378, 2386-2398. [CrossRef]

56. Hernandez Burgos, P.; Patel, J.; Chen, A. Ivosidenib induction therapy complicated by myopericarditis and cardiogenic shock: A case report and literature review. J. Oncol. Pharm. Pract. 2020, 26, 754-757. [CrossRef]

57. Galkin, M.; Jonas, B.A. Enasidenib in the treatment of relapsed/refractory acute myeloid leukemia: An evidence-based review of its place in therapy. Core Evid. 2019, 14, 3-17. [CrossRef]

58. Stein, E.M.; DiNardo, C.D.; Pollyea, D.A.; Fathi, A.T.; Roboz, G.J.; Altman, J.K.; Stone, R.M.; DeAngelo, D.J.; Levine, R.L.; Flinn, I.W.; et al. Enasidenib in mutant IDH2 relapsed or refractory acute myeloid leukemia. Blood 2017, 130, 722-731. [CrossRef]

59. Pollyea, D.A.; Tallman, M.S.; de Botton, S.; Kantarjian, H.M.; Collins, R.; Stein, A.S.; Frattini, M.G.; Xu, Q.; Tosolini, A.; See, W.L.; et al. Enasidenib, an inhibitor of mutant IDH2 proteins, induces durable remissions in older patients with newly diagnosed acute myeloid leukemia. Leukemia 2019, 33, 2575-2584. [CrossRef]

60. Giudice, V.; Pagliano, P.; Vatrella, A.; Masullo, A.; Poto, S.; Polverino, B.M.; Gammaldi, R.; Maglio, A.; Sellitto, C.; Vitale, C.; et al. Combination of Ruxolitinib and Eculizumab for Treatment of Severe SARS-CoV-2-Related Acute Respiratory Distress Syndrome: A Controlled Study. Front. Pharmacol. 2020, 11, 857. [CrossRef]

61. Anand, S.; Stedham, F.; Gudgin, E.; Campbell, P.; Beer, P.; Green, A.R.; Huntly, B.J. Increased basal intracellular signaling patterns do not correlate with JAK2 genotype in human myeloproliferative neoplasms. Blood 2011, 118, 1610-1621. [CrossRef] [PubMed]

62. Rodgers, G.P.; Young, N.S. The Bethesda Handbook of Clinical Hematology, 4th ed.; Lippincott Williams \& Wilkins (LWW): Philadelphia, PA, USA, 2018; ISBN 978-1-49-635400-6. 
63. Pardanani, A.; Tefferi, A. How I treat myelofibrosis after failure of JAK inhibitors. Blood 2018, 132, 492-500. [CrossRef] [PubMed]

64. Verstovsek, S.; Mesa, R.A.; Gotlib, J.; Levy, R.S.; Gupta, V.; Di Persio, J.F.; Catalano, J.V.; Deininger, M.; Miller, C.; Silver, R.T.; et al. A double-blind, placebo-controlled trial of ruxolitinib for myelofibrosis. N. Engl. J. Med. 2012, 366, 799-807. [CrossRef] [PubMed]

65. Vannucchi, A.M.; Kiladjian, J.J.; Griesshammer, M.; Masszi, T.; Durrant, S.; Passamonti, F.; Harrison, C.N.; Pane, F.; Zachee, P.; Mesa, R.; et al. Ruxolitinib versus standard therapy for the treatment of polycythemia vera. N. Engl. J. Med. 2015, 372, 426-435. [CrossRef]

66. von Bubnoff, N.; Ihorst, G.; Grishina, O.; Röthling, N.; Bertz, H.; Duyster, J.; Finke, J.; Zeiser, R. Ruxolitinib in GvHD (RIG) study: A multicenter, randomized phase 2 trial to determine the response rate of Ruxolitinib and best available treatment (BAT) versus BAT in steroid-refractory acute graft-versus-host disease (aGvHD) (NCT02396628). BMC Cancer 2018, 18, 1132. [CrossRef]

67. Sapre, M.; Tremblay, D.; Wilck, E.; James, A.; Leiter, A.; Coltoff, A.; Koshy, A.G.; Kremyanskaya, M.; Hoffman, R.; Mascarenhas, J.O.; et al. Metabolic Effects of JAK1/2 Inhibition in Patients with Myeloproliferative Neoplasms. Sci. Rep. 2019, 9, 16609. [CrossRef]

68. Punwani, N.; Yeleswaram, S.; Chen, X.; Bowman, J.; Soloviev, M.; Williams, W. Evaluation of the effect of ruxolitinib on cardiac repolarization: A thorough QT study. Clin. Pharmacol. Drug Dev. 2014, 3, 207-214. [CrossRef]

69. Miyawaki, H.; Kioka, H.; Sato, K.; Kurashige, M.; Ozawa, T.; Shibayama, H.; Hikoso, S.; Morii, E.; Yamauchi-Takihara, K.; Sakata, Y. Long-term Effects of the Janus Kinase 1/2 Inhibitor Ruxolitinib on Pulmonary Hypertension and the Cardiac Function in a Patient with Myelofibrosis. Intern. Med. 2020, 59, 229-233. [CrossRef]

70. Talpaz, M.; Kiladjian, J.J. Fedratinib, a newly approved treatment for patients with myeloproliferative neoplasm-associated myelofibrosis. Leukemia 2020, 2020, 1-17. [CrossRef]

71. Mullally, A.; Hood, J.; Harrison, C.; Mesa, R. Fedratinib in myelofibrosis. Blood Adv. 2020, 4, $1792-1800$. [CrossRef]

72. Schieber, M.; Crispino, J.D.; Stein, B. Myelofibrosis in 2019: Moving beyond JAK2 inhibition. Blood Cancer J. 2019, 9, 74. [CrossRef] [PubMed]

73. Bewersdorf, J.P.; Jaszczur, S.M.; Afifi, S.; Zhao, J.C.; Zeidan, A.M. Beyond Ruxolitinib: Fedratinib and Other Emergent Treatment Options for Myelofibrosis. Cancer Manag. Res. 2019, 11, 10777-10790. [CrossRef] [PubMed]

74. Pardanani, A.; Harrison, C.; Cortes, J.E.; Cervantes, F.; Mesa, R.A.; Milligan, D.; Masszi, T.; Mishchenko, E.; Jourdan, E.; Vannucchi, A.M.; et al. Safety and Efficacy of Fedratinib in Patients With Primary or Secondary Myelofibrosis: A Randomized Clinical Trial. JAMA Oncol. 2015, 1, 643-651. [CrossRef] [PubMed]

75. Iqbal, N.; Iqbal, N. Imatinib: A breakthrough of targeted therapy in cancer. Chemother. Res. Pract. 2014, 2014, 357027. [CrossRef]

76. Marcucci, G.; Perrotti, D.; Caligiuri, M.A. Understanding the molecular basis of imatinib mesylate therapy in chronic myelogenous leukemia and the related mechanisms of resistance. Commentary re: A. N. Mohamed et al., The effect of imatinib mesylate on patients with Philadelphia chromosome-positive chronic myeloid leukemia with secondary chromosomal aberrations. Clin. Cancer Res. 2003, 9, 1248-1252.

77. Kerkelä, R.; Grazette, L.; Yacobi, R.; Iliescu, C.; Patten, R.; Beahm, C.; Walters, B.; Shevtsov, S.; Pesant, S.; Clubb, F.J.; et al. Cardiotoxicity of the cancer therapeutic agent imatinib mesylate. Nat. Med. 2006, 12, 908-916. [CrossRef]

78. Distler, J.H.; Distler, O. Cardiotoxicity of imatinib mesylate: An extremely rare phenomenon or a major side effect? Ann. Rheum Dis. 2007, 66, 836. [CrossRef]

79. Ribeiro, A.L.; Marcolino, M.S.; Bittencourt, H.N.; Barbosa, M.M.; Nunes Mdo, C.; Xavier, V.F.; Clementino, N.C. An evaluation of the cardiotoxicity of imatinib mesylate. Leuk. Res. 2008, 32, 1809-1814. [CrossRef]

80. Francisco, A.R.G.; Alves, D.; David, C.; Guerra, L.; Pinto, F.J.; Almeida, A.G. Cardiotoxicity in Hematological Diseases: Are the Tyrosine Kinase Inhibitors Imatinib and Nilotinib Safe? Cardiovasc. Toxicol. 2018, 18, 431-435. [CrossRef]

81. Estabragh, Z.R.; Knight, K.; Watmough, S.J.; Lane, S.; Vinjamuri, S.; Hart, G.; Clark, R.E. A prospective evaluation of cardiac function in patients with chronic myeloid leukaemia treated with imatinib. Leuk. Res. 2011, 35, 49-51. [CrossRef] 
82. Orphanos, G.S.; Ioannidis, G.N.; Ardavanis, A.G. Cardiotoxicity induced by tyrosine kinase inhibitors. Acta Oncol. 2009, 48, 964-970. [CrossRef] [PubMed]

83. Atallah, E.; Durand, J.B.; Kantarjian, H.; Cortes, J. Congestive heart failure is a rare event in patients receiving imatinib therapy. Blood 2007, 110, 1233-1237. [CrossRef] [PubMed]

84. Maharsy, W.; Aries, A.; Mansour, O.; Komati, H.; Nemer, M. Ageing is a risk factor in imatinib mesylate cardiotoxicity. Eur. J. Heart Fail. 2014, 16, 367-376. [CrossRef] [PubMed]

85. Xu, Z.; Cang, S.; Yang, T.; Liu, D. Cardiotoxicity of tyrosine kinase inhibitors in chronic myelogenous leukemia therapy. Hematol. Rev. 2009, 1, e4. [CrossRef]

86. Magdy, T.; Burmeister, B.T.; Burridge, P.W. Validating the pharmacogenomics of chemotherapy-induced cardiotoxicity: What is missing? Pharmacol. Ther. 2016, 168, 113-125. [CrossRef] [PubMed]

87. Brave, M.; Goodman, V.; Kaminskas, E.; Farrell, A.; Timmer, W.; Pope, S.; Harapanhalli, R.; Saber, H.; Morse, D.; Bullock, J.; et al. Sprycel for chronic myeloid leukemia and Philadelphia chromosome-positive acute lymphoblastic leukemia resistant to or intolerant of imatinib mesylate. Clin. Cancer Res. 2008, 14, 352-359. [CrossRef] [PubMed]

88. Krauth, M.T.; Herndlhofer, S.; Schmook, M.T.; Mitterbauer-Hohendanner, G.; Schlögl, E.; Valent, P. Extensive pleural and pericardial effusion in chronic myeloid leukemia during treatment with dasatinib at $100 \mathrm{mg}$ or $50 \mathrm{mg}$ daily. Haematologica 2011, 96, 163-166. [CrossRef]

89. Quintás-Cardama, A.; Kantarjian, H.; O’brien, S.; Borthakur, G.; Bruzzi, J.; Munden, R.; Cortes, J. Pleural effusion in patients with chronic myelogenous leukemia treated with dasatinib after imatinib failure. J. Clin. Oncol. 2007, 25, 3908-3914. [CrossRef]

90. Cortes, J.E.; Jimenez, C.A.; Mauro, M.J.; Geyer, A.; Pinilla-Ibarz, J.; Smith, B.D. Pleural Effusion in Dasatinib-Treated Patients With Chronic Myeloid Leukemia in Chronic Phase: Identification and Management. Clin. Lymphoma Myeloma Leuk. 2017, 17, 78-82. [CrossRef]

91. Porkka, K.; Khoury, H.J.; Paquette, R.L.; Matloub, Y.; Sinha, R.; Cortes, J.E. Dasatinib 100 mg once daily minimizes the occurrence of pleural effusion in patients with chronic myeloid leukemia in chronic phase and efficacy is unaffected in patients who develop pleural effusion. Cancer 2010, 116, 377-386. [CrossRef]

92. Visani, G.; Breccia, M.; Montefusco, E.; Morra, E.; Santini, V.; Isidori, A. The incidence of pleural and pericardial effusion is not higher in patients receiving dasatinib at low doses. (Reply). Haematologica 2011, 96, e23-e24, author reply e25. [CrossRef] [PubMed]

93. Kantarjian, H.; Giles, F.; Wunderle, L.; Bhalla, K.; O’Brien, S.; Wassmann, B.; Tanaka, C.; Manley, P.; Rae, P.; Mietlowski, W.; et al. Nilotinib in imatinib-resistant CML and Philadelphia chromosome-positive ALL. N. Engl. J. Med. 2006, 354, 2542-2551. [CrossRef] [PubMed]

94. Shopp, G.M.; Helson, L.; Bouchard, A.; Salvail, D.; Majeed, M. Liposomes ameliorate Crizotinib- and Nilotinib-induced inhibition of the cardiac IKr channel and QTc prolongation. Anticancer Res. 2014, 34, 4733-4740. [PubMed]

95. Valent, P.; Hadzijusufovic, E.; Schernthaner, G.H.; Wolf, D.; Rea, D.; le Coutre, P. Vascular safety issues in CML patients treated with BCR/ABL1 kinase inhibitors. Blood 2015, 125, 901-906. [CrossRef]

96. Doherty, K.R.; Wappel, R.L.; Talbert, D.R.; Trusk, P.B.; Moran, D.M.; Kramer, J.W.; Brown, A.M.; Shell, S.A.; Bacus, S. Multi-parameter in vitro toxicity testing of crizotinib, sunitinib, erlotinib, and nilotinib in human cardiomyocytes. Toxicol. Appl. Pharmacol. 2013, 272, 245-255. [CrossRef] [PubMed]

97. Kim, T.D.; le Coutre, P.; Schwarz, M.; Grille, P.; Levitin, M.; Fateh-Moghadam, S.; Giles, F.J.; Dörken, B.; Haverkamp, W.; Köhncke, C. Clinical cardiac safety profile of nilotinib. Haematologica 2012, 97, 883-889. [CrossRef] [PubMed]

98. Aichberger, K.J.; Herndlhofer, S.; Schernthaner, G.H.; Schillinger, M.; Mitterbauer-Hohendanner, G.; Sillaber, C.; Valent, P. Progressive peripheral arterial occlusive disease and other vascular events during nilotinib therapy in CML. Am. J. Hematol. 2011, 86, 533-539. [CrossRef]

99. Cortes, J.E.; Jean Khoury, H.; Kantarjian, H.; Brümmendorf, T.H.; Mauro, M.J.; Matczak, E.; Pavlov, D.; Aguiar, J.M.; Fly, K.D.; Dimitrov, S.; et al. Long-term evaluation of cardiac and vascular toxicity in patients with Philadelphia chromosome-positive leukemias treated with bosutinib. Am. J. Hematol. 2016, 91, 606-616. [CrossRef] [PubMed]

100. Mahida, H.; Gharia, B.; Ugoeke, N.; Maludum, O.; Asif, A.; Calderon, D. Abstract 11853: Cardiovascular Adverse Events Associated With First, Second and Third Generation Tyrosine Kinase Inhibitors Used in Treatment of Chronic Myeloid Leukemia. Circulation 2018, 138, A11853. 
101. Tan, F.H.; Putoczki, T.L.; Stylli, S.S.; Luwor, R.B. Ponatinib: A novel multi-tyrosine kinase inhibitor against human malignancies. Onco Targets Ther. 2019, 12, 635-645. [CrossRef]

102. Tamai, M.; Inukai, T.; Kojika, S.; Abe, M.; Kagami, K.; Harama, D.; Shinohara, T.; Watanabe, A.; Oshiro, H.; Akahane, K.; et al. T315I mutation of BCR-ABL1 into human Philadelphia chromosome-positive leukemia cell lines by homologous recombination using the CRISPR/Cas9 system. Sci. Rep. 2018, 8, 9966. [CrossRef] [PubMed]

103. Singh, A.P.; Umbarkar, P.; Tousif, S.; Lal, H. Cardiotoxicity of the BCR-ABL1 tyrosine kinase inhibitors: Emphasis on ponatinib. Int. J. Cardiol. 2020, 316, 214-221. [CrossRef] [PubMed]

104. Jin, Y.; Xu, Z.; Yan, H.; He, Q.; Yang, X.; Luo, P. A Comprehensive Review of Clinical Cardiotoxicity Incidence of FDA-Approved Small-Molecule Kinase Inhibitors. Front. Pharmacol. 2020, 11, 891. [CrossRef] [PubMed]

105. Dorer, D.J.; Knickerbocker, R.K.; Baccarani, M.; Cortes, J.E.; Hochhaus, A.; Talpaz, M.; Haluska, F.G. Impact of dose intensity of ponatinib on selected adverse events: Multivariate analyses from a pooled population of clinical trial patients. Leuk. Res. 2016, 48, 84-91. [CrossRef] [PubMed]

106. Cortes, J.E.; Kim, D.W.; Pinilla-Ibarz, J.; le Coutre, P.D.; Paquette, R.; Chuah, C.; Nicolini, F.E.; Apperley, J.F.; Khoury, H.J.; Talpaz, M.; et al. Ponatinib efficacy and safety in Philadelphia chromosome-positive leukemia: Final 5-year results of the phase 2 PACE trial. Blood 2018, 132, 393-404. [CrossRef]

107. Cortes, J.E.; Kim, D.W.; Pinilla-Ibarz, J.; le Coutre, P.; Paquette, R.; Chuah, C.; Nicolini, F.E.; Apperley, J.F.; Khoury, H.J.; Talpaz, M.; et al. A phase 2 trial of ponatinib in Philadelphia chromosome-positive leukemias. N. Engl. J. Med. 2013, 369, 1783-1796. [CrossRef]

108. Caocci, G.; Mulas, O.; Bonifacio, M.; Abruzzese, E.; Galimberti, S.; Orlandi, E.M.; Iurlo, A.; Annunziata, M.; Luciano, L.; Castagnetti, F.; et al. Recurrent arterial occlusive events in patients with chronic myeloid leukemia treated with second- and third-generation tyrosine kinase inhibitors and role of secondary prevention. Int. J. Cardiol. 2019, 288, 124-127. [CrossRef]

109. Caocci, G.; Mulas, O.; Abruzzese, E.; Luciano, L.; Iurlo, A.; Attolico, I.; Castagnetti, F.; Galimberti, S.; Sgherza, N.; Bonifacio, M.; et al. Arterial occlusive events in chronic myeloid leukemia patients treated with ponatinib in the real-life practice are predicted by the Systematic Coronary Risk Evaluation (SCORE) chart. Hematol. Oncol. 2019, 37, 296-302. [CrossRef]

110. Tzogani, K.; Røshol, H.; Olsen, H.H.; Aas, I.B.; Dalhus, M.L.; Håkonsen, G.D.; Nilssen, L.S.; Lindberg, V.; Økvist, M.; Bolstad, B.; et al. The European Medicines Agency Review of Gilteritinib (Xospata) for the Treatment of Adult Patients with Relapsed or Refractory Acute Myeloid Leukemia with an FLT3 Mutation. Oncologist 2020, 25, e1070-e1076. [CrossRef]

111. Perl, A.E.; Martinelli, G.; Cortes, J.E.; Neubauer, A.; Berman, E.; Paolini, S.; Montesinos, P.; Baer, M.R.; Larson, R.A.; Ustun, C.; et al. Gilteritinib or Chemotherapy for Relapsed or Refractory FLT3-Mutated AML. N. Engl. J. Med. 2019, 381, 1728-1740. [CrossRef]

112. Cortes, J.E.; Heidel, F.H.; Hellmann, A.; Fiedler, W.; Smith, B.D.; Robak, T.; Montesinos, P.; Pollyea, D.A.; DesJardins, P.; Ottmann, O.; et al. Randomized comparison of low dose cytarabine with or without glasdegib in patients with newly diagnosed acute myeloid leukemia or high-risk myelodysplastic syndrome. Leukemia 2019, 33, 379-389. [CrossRef] [PubMed]

113. Fostvedt, L.; Shaik, N.; Martinelli, G.; Wagner, A.; Ruiz-Garcia, A. Abstract 3889: Population pharmacokinetic/pharmacodynamic evaluation of the effect of glasdegib exposure on cardiac repolarization (QT interval) in cancer patients. Cancer Res. 2019, 79, 3889.

114. del Corral, A.; Dutreix, C.; Huntsman-Labed, A.; Lorenzo, S.; Morganroth, J.; Harrell, R.; Wang, Y. Midostaurin does not prolong cardiac repolarization defined in a thorough electrocardiogram trial in healthy volunteers. Cancer Chemother. Pharmacol. 2012, 69, 1255-1263. [CrossRef] [PubMed]

115. Gallogly, M.M.; Lazarus, H.M. Midostaurin: An emerging treatment for acute myeloid leukemia patients. J. Blood Med. 2016, 7, 73-83. [PubMed]

116. Weisberg, E.; Boulton, C.; Kelly, L.M.; Manley, P.; Fabbro, D.; Meyer, T.; Gilliland, D.G.; Griffin, J.D. Inhibition of mutant FLT3 receptors in leukemia cells by the small molecule tyrosine kinase inhibitor PKC412. Cancer Cell 2002, 1, 433-443. [CrossRef]

117. Vaidya, P.; Khedro, T.; Yaghmour, B.; Yaghmour, G. Midostaurin-Related Interstitial Lung Injury in FLT3+ Acute Myeloid Leukemia Post-Allogeneic Transplant. World J. Oncol. 2019, 10, 237-239. [CrossRef]

118. Gandolfi, S.; Laubach, J.P.; Hideshima, T.; Chauhan, D.; Anderson, K.C.; Richardson, P.G. The proteasome and proteasome inhibitors in multiple myeloma. Cancer Metastasis Rev. 2017, 36, 561-584. [CrossRef] 
119. Plummer, C.; Driessen, C.; Szabo, Z.; Mateos, M.V. Management of cardiovascular risk in patients with multiple myeloma. Blood Cancer J. 2019, 9, 26. [CrossRef]

120. Nowis, D.; Maczewski, M.; Mackiewicz, U.; Kujawa, M.; Ratajska, A.; Wieckowski, M.R.; Wilczyński, G.M.; Malinowska, M.; Bil, J.; Salwa, P.; et al. Cardiotoxicity of the anticancer therapeutic agent bortezomib. Am. J. Pathol. 2010, 176, 2658-2668. [CrossRef]

121. Xiao, Y.; Yin, J.; Wei, J.; Shang, Z. Incidence and risk of cardiotoxicity associated with bortezomib in the treatment of cancer: A systematic review and meta-analysis. PLoS ONE 2014, 9, e87671. [CrossRef]

122. Jaramillo Restrepo, V.; Shah, V.S.; Jain, T.; Larsen, J.T.; Narayanasamy, H.; Arsanjani, R.; Hardaway, B.W.; Mookadam, F.; Larsen, C. Cardiovascular outcomes following bortezomib reinitiation after congestive heart failure diagnosis in multiple myeloma. J. Am. Coll. Cardiol. 2020, 75, 723. [CrossRef]

123. Reneau, J.; Asante, D.; Van Houten, H.; Buadi, F.; Lerman, A.; Herrmann, J. Cardiotoxicity Risk with Bortezomib Versus Lenalidomide for Treatment of Multiple Myeloma: A Propensity-Matched Study of 1128 Patients. Blood 2015, 126, 3046. [CrossRef]

124. Land, J.; Afifi, S.; Adel, N.G.; Devlin, S.; Arora, A.; Lendvai, N.; Landgren, O. Incidence and Management of Proteasome Inhibitor-Related Cardiotoxicity in Multiple Myeloma Patients at Memorial Sloan Kettering Cancer Center. Blood 2015, 126, 4265. [CrossRef]

125. Wu, P.; Oren, O.; Gertz, M.A.; Yang, E.H. Proteasome Inhibitor-Related Cardiotoxicity: Mechanisms, Diagnosis, and Management. Curr. Oncol. Rep. 2020, 22, 66. [CrossRef] [PubMed]

126. Bockorny, M.; Chakravarty, S.; Schulman, P.; Bockorny, B.; Bona, R. Severe heart failure after bortezomib treatment in a patient with multiple myeloma: A case report and review of the literature. Acta Haematol. 2012, 128, 244-247. [CrossRef]

127. Jerkins, J.H.; Suciu, A.; Mazimba, S.; Calvo, A. Bortezomib-induced Severe Congestive Heart Failure. Cardiol. Res. 2010, 1, 20-23. [CrossRef]

128. Diwadkar, S.; Patel, A.A.; Fradley, M.G. Bortezomib-Induced Complete Heart Block and Myocardial Scar: The Potential Role of Cardiac Biomarkers in Monitoring Cardiotoxicity. Case Rep. Cardiol. 2016, 2016, 3456287. [CrossRef]

129. Buza, V.; Rajagopalan, B.; Curtis, A.B. Cancer Treatment-Induced Arrhythmias: Focus on Chemotherapy and Targeted Therapies. Circ. Arrhythm. Electrophysiol. 2017, 10, e005443. [CrossRef]

130. Chen, J.H.; Lenihan, D.J.; Phillips, S.E.; Harrell, S.L.; Cornell, R.F. Cardiac events during treatment with proteasome inhibitor therapy for multiple myeloma. Cardiooncology 2017, 3, 4. [CrossRef]

131. Jakubowiak, A.J.; DeCara, J.M.; Mezzi, K. Cardiovascular events during carfilzomib therapy for relapsed myeloma: Practical management aspects from two case studies. Hematology 2017, 22, 585-591. [CrossRef]

132. Siegel, D.; Martin, T.; Nooka, A.; Harvey, R.D.; Vij, R.; Niesvizky, R.; Badros, A.Z.; Jagannath, S.; McCulloch, L.; Rajangam, K.; et al. Integrated safety profile of single-agent carfilzomib: Experience from 526 patients enrolled in 4 phase II clinical studies. Haematologica 2013, 98, 1753-1761. [CrossRef] [PubMed]

133. Dimopoulos, M.A.; Moreau, P.; Palumbo, A.; Joshua, D.; Pour, L.; Hájek, R.; Facon, T.; Ludwig, H.; Oriol, A.; Goldschmidt, H.; et al. Carfilzomib and dexamethasone versus bortezomib and dexamethasone for patients with relapsed or refractory multiple myeloma (ENDEAVOR): A randomised, phase 3, open-label, multicentre study. Lancet Oncol. 2016, 17, 27-38. [CrossRef]

134. Bringhen, S.; Milan, A.; Ferri, C.; Wäsch, R.; Gay, F.; Larocca, A.; Salvini, M.; Terpos, E.; Goldschmidt, H.; Cavo, M.; et al. Cardiovascular adverse events in modern myeloma therapy-Incidence and risks. A review from the European Myeloma Network (EMN) and Italian Society of Arterial Hypertension (SIIA). Haematologica 2018, 103, 1422-1432. [CrossRef] [PubMed]

135. Quach, H.; Ritchie, D.; Stewart, A.K.; Neeson, P.; Harrison, S.; Smyth, M.J.; Prince, H.M. Mechanism of action of immunomodulatory drugs (IMiDS) in multiple myeloma. Leukemia 2010, 24, 22-32. [CrossRef]

136. Di Lullo, G.; Marcatti, M.; Heltai, S.; Tresoldi, C.; Paganoni, A.M.; Bordignon, C.; Ciceri, F.; Protti, M.P. Immunomodulatory Drugs in the Context of Autologous Hematopoietic Stem Cell Transplantation Associate With Reduced Pro-tumor T Cell Subsets in Multiple Myeloma. Front. Immunol. 2019, 9, 3171. [CrossRef]

137. Delforge, M.; Ludwig, H. How I manage the toxicities of myeloma drugs. Blood 2017, 129, $2359-2367$. [CrossRef]

138. Li, W.; Cornell, R.F.; Lenihan, D.; Slosky, D.; Jagasia, M.; Piazza, G.; Moslehi, J. Cardiovascular Complications of Novel Multiple Myeloma Treatments. Circulation 2016, 133, 908-912. [CrossRef] 
139. Reneau, J.C.; Asante, D.; van Houten, H.; Sangaralingham, L.R.; Buadi, F.K.; Lerman, A.; Herrmann, J. Cardiotoxicity risk with bortezomib versus lenalidomide for treatment of multiple myeloma: A propensity matched study of 1790 patients. Am. J. Hematol. 2017, 92, 15-17. [CrossRef]

140. Li, W.; Garcia, D.; Cornell, R.F.; Gailani, D.; Laubach, J.; Maglio, M.E.; Richardson, P.G.; Moslehi, J. Cardiovascular and Thrombotic Complications of Novel Multiple Myeloma Therapies: A Review. JAMA Oncol. 2017, 3, 980-988. [CrossRef]

141. Fradley, M.G.; Groarke, J.D.; Laubach, J.; Alsina, M.; Lenihan, D.J.; Cornell, R.F.; Maglio, M.; Shain, K.H.; Richardson, P.G.; Moslehi, J. Recurrent cardiotoxicity potentiated by the interaction of proteasome inhibitor and immunomodulatory therapy for the treatment of multiple myeloma. Br. J. Haematol. 2018, 180, 271-275. [CrossRef]

142. El Accaoui, R.N.; Shamseddeen, W.A.; Taher, A.T. Thalidomide and thrombosis. A meta-analysis. Thromb. Haemost. 2007, 97, 1031-1036. [PubMed]

143. Dimopoulos, M.A.; Chen, C.; Spencer, A.; Niesvizky, R.; Attal, M.; Stadtmauer, E.A.; Petrucci, M.T.; Yu, Z.; Olesnyckyj, M.; Zeldis, J.B.; et al. Long-term follow-up on overall survival from the MM-009 and MM-010 phase III trials of lenalidomide plus dexamethasone in patients with relapsed or refractory multiple myeloma. Leukemia 2009, 23, 2147-2152. [CrossRef] [PubMed]

144. Sato, T.; Issa, J.J.; Kropf, P. DNA Hypomethylating Drugs in Cancer Therapy. Cold Spring Harb. Perspect. Med. 2017, 7, a026948. [CrossRef] [PubMed]

145. Kambara, Y.; Yamamoto, A.; Masunari, T.; Sezaki, N.; Sugiura, H.; Ikegawa, S.; Meguri, Y.; Kiguchi, T.; Maeda, Y. A Risk-Scoring System to Predict Heart Failure Onset during Treatment of Myelodysplastic Syndrome with Azacitidine. Ann. Hematol. Oncol. 2019, 6, 1248.

146. Newman, M.; Malla, M.; Gojo, I. Azacitidine-Induced Pericarditis: A Case Series. Pharmacotherapy 2016, 36, 443-448. [CrossRef]

147. Agasthi, P.; Narayanasamy, H.; Sorajja, D.; Slack, J.; Mookadam, F. Decitabine Induced Delayed Cardiomyopathy in Hematologic Malignancy. Case Rep. Cardiol. 2018, 2018, 3953579. [CrossRef]

148. Cuesta-Mateos, C.; Alcaraz-Serna, A.; Somovilla-Crespo, B.; Muñoz-Calleja, C. Monoclonal Antibody Therapies for Hematological Malignancies: Not Just Lineage-Specific Targets. Front. Immunol. 2018, 8, 1936. [CrossRef]

149. Weiner, G.J. Monoclonal antibody mechanisms of action in cancer. Immunol. Res. 2007, 39, 271-278. [CrossRef]

150. Craig, F.E.; Foon, K.A. Flow cytometric immunophenotyping for hematologic neoplasms. Blood 2008, 111, 3941-3967. [CrossRef]

151. Du, F.H.; Mills, E.A.; Mao-Draayer, Y. Next-generation anti-CD20 monoclonal antibodies in autoimmune disease treatment. Auto Immun. Highlights 2017, 8, 12. [CrossRef]

152. Alduaij, W.; Illidge, T.M. The future of anti-CD20 monoclonal antibodies: Are we making progress? Blood 2011, 117, 2993-3001. [CrossRef] [PubMed]

153. van de Donk, N.W.C.J.; Usmani, S.Z. CD38 Antibodies in Multiple Myeloma: Mechanisms of Action and Modes of Resistance. Front. Immunol. 2018, 9, 2134. [CrossRef] [PubMed]

154. Jelínek, T.; Mihályová, J.; Hájek, R. CD38 targeted treatment for multiple myeloma. Vnitr. Lek. 2018, 64, 939-948. [PubMed]

155. Trudel, S.; Moreau, P.; Touzeau, C. Update on elotuzumab for the treatment of relapsed/refractory multiple myeloma: Patients' selection and perspective. Onco Targets Ther. 2019, 12, 5813-5822. [CrossRef]

156. Richardson, P.G.; Lee, H.C.; Abdallah, A.O.; Cohen, A.D.; Kapoor, P.; Voorhees, P.M.; Hoos, A.; Wang, K.; Baron, J.; Piontek, T.; et al. Single-agent belantamab mafodotin for relapsed/refractory multiple myeloma: Analysis of the lyophilised presentation cohort from the pivotal DREAMM-2 study. Blood Cancer J. 2020, 10, 106. [CrossRef]

157. Scott, L.J. Brentuximab Vedotin: A Review in CD30-Positive Hodgkin Lymphoma. Drugs 2017, 77, 435-445. [CrossRef]

158. van de Donk, N.W.; Dhimolea, E. Brentuximab vedotin. MAbs 2012, 4, 458-465. [CrossRef]

159. De Re, V.; Caggiari, L.; Repetto, O.; Mussolin, L.; Mascarin, M. Classical Hodgkin's Lymphoma in the Era of Immune Checkpoint Inhibition. J. Clin. Med. 2019, 8, 1596. [CrossRef] 
160. Salles, G.; Duell, J.; González Barca, E.; Tournilhac, O.; Jurczak, W.; Liberati, A.M.; Nagy, Z.; Obr, A.; Gaidano, G.; André, M.; et al. Tafasitamab plus lenalidomide in relapsed or refractory diffuse large B-cell lymphoma (L-MIND): A multicentre, prospective, single-arm, phase 2 study. Lancet Oncol. 2020, 21, 978-988. [CrossRef]

161. Douglas, M. Polatuzumab Vedotin for the Treatment of Relapsed/Refractory Diffuse Large B-Cell Lymphoma in Transplant-Ineligible Patients. J. Adv. Pract. Oncol. 2020, 11, 521-528.

162. Trapani, D.; Zagami, P.; Nicolò, E.; Pravettoni, G.; Curigliano, G. Management of Cardiac Toxicity Induced by Chemotherapy. J. Clin. Med. 2020, 9, 2885. [CrossRef] [PubMed]

163. Avila, M.S.; Ayub-Ferreira, S.M.; de Barros Wanderley, M.R., Jr.; das Dores Cruz, F.; Gonçalves Brandão, S.M.; Rigaud, V.O.C.; Higuchi-Dos-Santos, M.H.; Hajjar, L.A.; Kalil Filho, R.; Hoff, P.M.; et al. Carvedilol for Prevention of Chemotherapy-Related Cardiotoxicity: The CECCY Trial. J. Am. Coll. Cardiol. 2018, 71, 2281-2290. [CrossRef] [PubMed]

164. Carrasco, R.; Ramirez, M.C.; Nes, K.; Schuster, A.; Aguayo, R.; Morales, M.; Ramos, C.; Hasson, D.; Sotomayor, C.G.; Henriquez, P.; et al. Prevention of doxorubicin-induced Cardiotoxicity by pharmacological non-hypoxic myocardial preconditioning based on Docosahexaenoic Acid (DHA) and carvedilol direct antioxidant effects: Study protocol for a pilot, randomized, double-blind, controlled trial (CarDHA trial). Trials 2020, 21, 137. [PubMed]

Publisher's Note: MDPI stays neutral with regard to jurisdictional claims in published maps and institutional affiliations. 